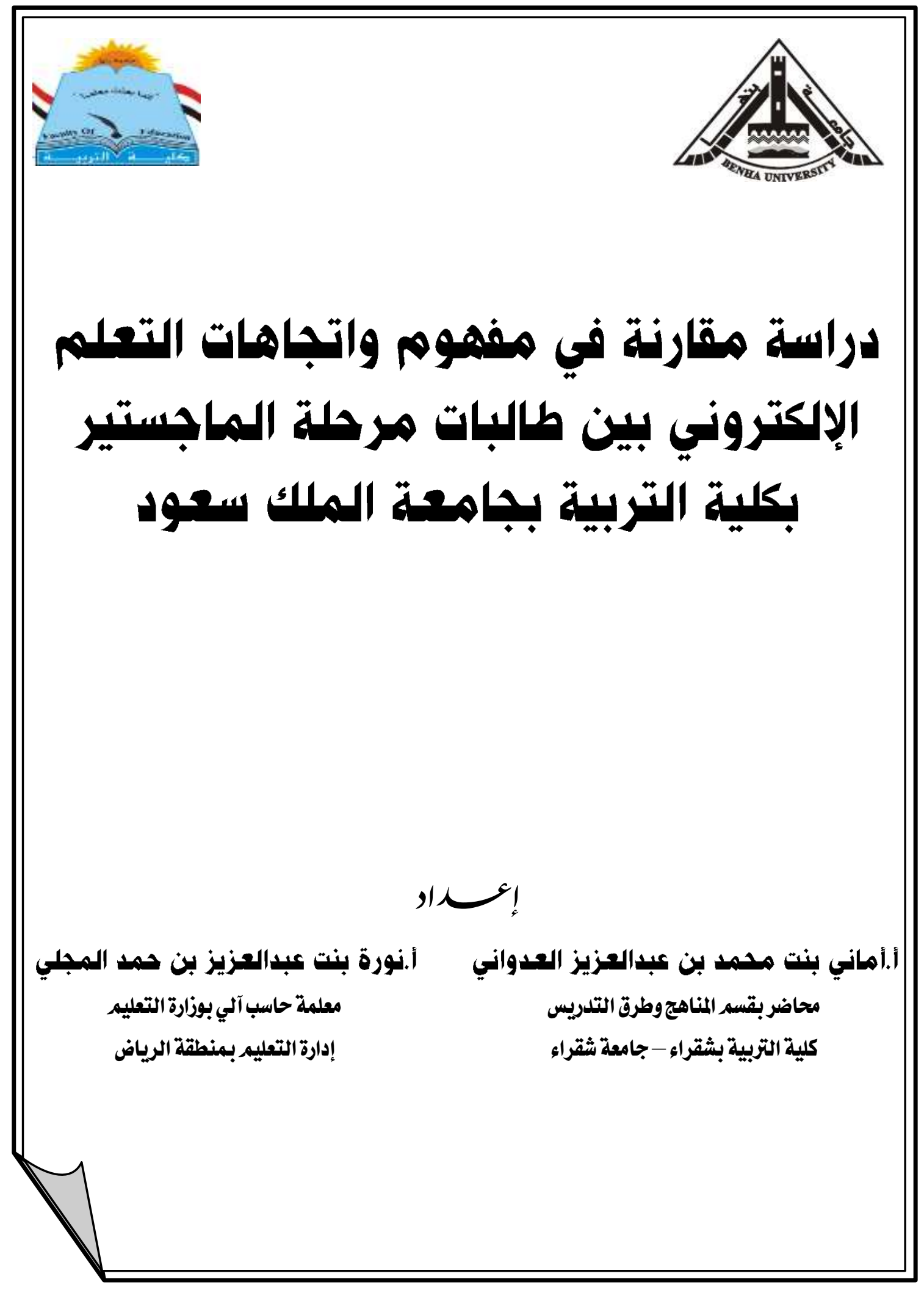


مصادر السعادة لدي ذوي الاعاقة السمعية الراشدين من منظور شخصي (دراسة حالة) ! إنسان

أ.نورة بنت عبدالعزيز بن حمد المجلي معلمة حاسب آلي بوزارة التعليه أأهماني بنت محمد بن عبدالعزيز العدواني إدارة التعليم بمنطقة الرياض محاضر بقسم المناهج وطرق التدريس كلية التربية بشقراء - جامعة شقراء

\section{ملزـــص البحـثب}

هدفت الدراسة إلى عمل مقارنة بين الطالبات المستخدمات لنظام إدارة التعلم LMS والطالبات الغير مستخدمات لمعرفة مدى التباين في مفهوم التعلم المدمج Blended Learning واتجاهـات الطالبات نحو استخدام بيئة التعلم المدمج Blended Learning. ولتحقيق أهداف الدراسة اتبعت الباحثبان المنهج شبه التجريبي، حيث تمثل مجتمع البحث في طالبات الماجستير بكلية التربية بجامعة الملك سعود، أما عينة البحث فتكونت من مجموعتين من طالبات الدراسات العليا

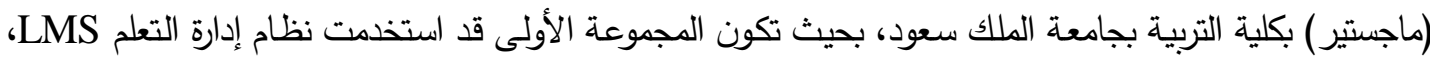

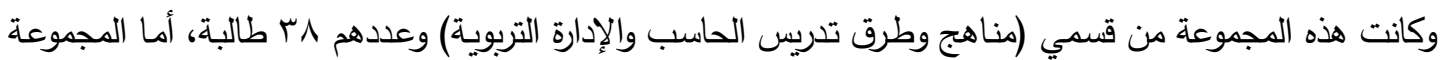

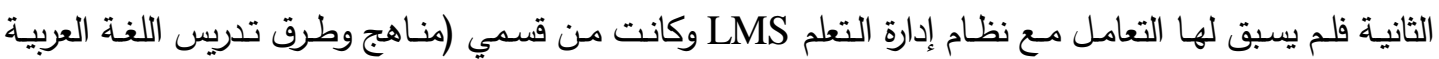

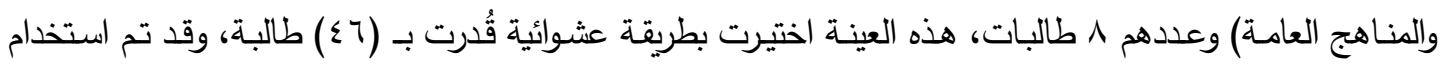

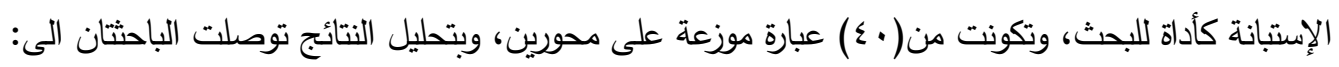

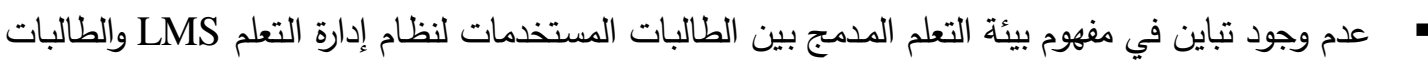
الغير مستخدمات، ويمكن تقسير ذلك بوجودنـا في عصر يحتم علينـا استخدام التقنية بأنواعها في التعليم ودمجهامع التعليم التقليدي، لذا تكونت لدى المجموعتين خلفية لا بأس بها حول مفهوم بيئة التعلم المدمج.

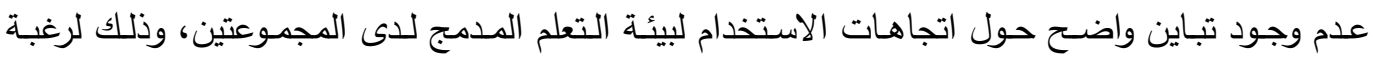
المجموعة الغير مستخدمة لنظام إدارة التعلم LMS لتجربة هذا النظام. بناء على رأي الطالبات المستخدمات لنظام إدارة التعلم LMS فإنـه يوجد فرق في التحصيل بين المواد

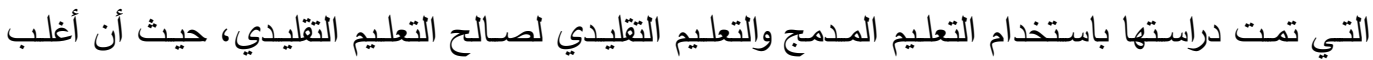
الطالبات حصلن على درجات أعلى في المقرر الذي تم دراسته باستخدام التعليم التقليدي. وفي نهاية الدراسة أكدت الباحثتان: • تأكيد ضرورة الاهتمام من قبل الجامعات بإدخال أسلوب التعليم الإلكتروني بنمط التعليم المدمج.

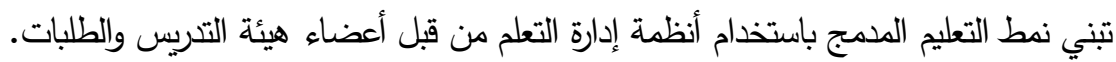

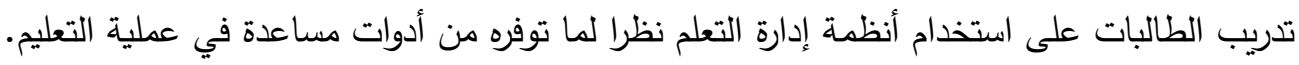
عقد دورات تدريبية لأعضاء هيئة التدريس لتدريبهم على استخدام أنظمة إدارة التعلم. • القيام بدراسات تتتاول استخدام استراتيجية التعليم المدمج وبحث أثرها على متغيرات أخرى.

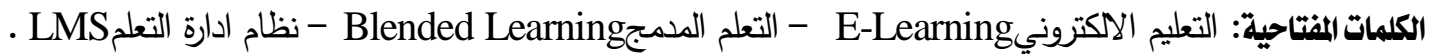




\section{Abstract}

The study aimed at a comparison between students employed for learning management system LMS students and other sare employed to determine thevariation in the concept of learning built Blended Learning and student attitudes towards the use of the learning environment built Blended Learning.

To achieve the objectives of the study followed the researchers approach quasi-experimental, representing the research community in the students master the Faculty of Education, King Saud University, and the research sample two groups of graduate students (Master), Faculty of Education, King Saud University, so that the first group has used learning management system, was this group of sections (curricula and methods of teaching computer and educational administration) and numbered 38 students, while the second group has never have to deal with the learning management system and was one of the sections (curricula and methods of teaching the Arabic language and curriculum public) and the number 8 students, this sampler selected estimated (46) students, the questionnaire has been used as a research tool, and consisted of (40) is distributed on two axes, and analyze the results the researchers reached:

- the lack of variation in the concept of the learning environment built between students employed for the learning management system and female nonemployed, and can be explained by our presence in the era requires us to use technology of all kinds in education, combined with traditional education, so formed by the two background not too bad on the concept of the learning environment Built.

- the lack of a clear contrast on trends in use of the learning environment built in both groups, and the desire of the group unused to learning management system to experience this system.

- Based on the opinion of students employed for learning management system, it makes no difference in achievement between the materials that have been studied using the built-in education and traditional education in favor of traditional education, where most of the students who received the highest grades in the decision that has been studied using traditional education.

At the end of the study confirmed the researchers:

- the need for attention by universities enter the e-learning style blended learning style.

- Adoption of a blended learning style by using learning management systems by faculty members and applications.

- Training students to use learning management systems as they provided tools to help in the education process.

- training sessions for faculty members to be trained in the use of learning management systems.

- Conduct studies on the use of blended learning strategy and discuss their impact on other variables.

Key words: E-Learning -Blended Learning - LMS. 


\section{مسلدخل الـدراسـيسة}

إن التطورات المهمة التي حدثت في تقنيات الحاسب الآلي والاتصالات والتي تُوجت بشبكة الإنترانت والإنترنت حولت العالم إلى قريـة صـغيرة، وخـلال العقدين المنصـرمين كان هنالك اهتمام كبير باستخدام الحاسوب في التعليم والتعلم، وقد أخذ أشكالاً عدة منها: التعلم عن بعد، والتعلم بمساعدة الحاسوب، والتعلم عبر الانترنت، إلى التعلم الالكتروني والتعلم باستخدام الواقع الافتراضي. لقد ظهر مصطلح التعلم الالكتروني في بدايـة عقد التسعينات، وأخذ يتردد كثيراً بعد النتائج الجيدة التي حققها وظهور أثاره الإيجابية في دعم العملية التعليمية، وقد استثر التعليم هذا التقدم من خلال الاستفادة من هذه التقنيات داخل القاعة الدراسية، وفي المختبرات وكذلك في الأنشطة المنهجية اللاصفية.

ومع التطور العلمي والتقدم التكنولوجي الذي يشهده العالم خاصـة في مجال تكنولوجيا المعلومات والاتصالات، فقد استثرت بعض الجامعات هذا التقدم في الأسـاليب والتكنولوجيا التعليميـة والتي مـن خلالهـا أتاحت الوسـائل المختلفـة، التي تسـاعد في تقديم المـادة العلميـة للطالب بصـورة سـهلة وسـريعة وواضـحة، بـرزت أشكال مختلفـة مـن التعليم الالكترونيتناسـب حاجـات المتعلمين، وطبيعـة الأدوات المتـوافرة للاتصـال، ومـن بـين هـه الأشـكال مـا يسـى بـالتعليم المدمج Blended Learning الذي فتح آفاقاً جديدة للمتعلمين، لم تكن متاحسة مـن قبـل، وخضـعت المنـاهج التعليميـة لإعـادة نظـر ؛ لتواكـب المتطلبـات الحديثـة فـي مجتمـحع المعلومات، وتم الاهتمام بتزويد الأفراد بالمهارات التي تؤهلهم لاستخدام تكنولوجيا المعلومات، وبدأ سوق العمل من خـلال حاجاته لمهارات ومؤهلات جديدة، بفرضتوجهات واختصاصـات مستحدثة في مجال التعليم الجامعي. كذلك وتعد أنظمـة إدارة التعلم (Learning Management System) مسن أهم الأنظمة الحالية التي ساعدت الأستاذ والطالب على التواصل وجعل عملية التعليم أكثر كفاءة وسرعة وسـاعدت على إرشـاد الطلبة إلى التعلم الذاتي وأتـاح للأسـاتذة أن يعطوا ملاحظـاتهم لأكبر عدد ممكن من الطلبة في نفس الوقت. إن القدرة على مواكبة المستجدات السريعة في التكنولوجيا الحديثة يعتمد بشكل رئيسي على الوعي بحجم التحديات والصعوبات التي تواجهنا في جميع المجالات، فالتطورات المتلاحقة 
في مجال تتنيات الحاسوب والاتصـالات أصبحت تحتاج إلى مثابرة وجهد متواصل لضـمان متابعتها والتقاعل معها وتوظيفها لخدمة المجتمع، وقد انعكس ذلك على بلى برامج التعليم الالكتروني.

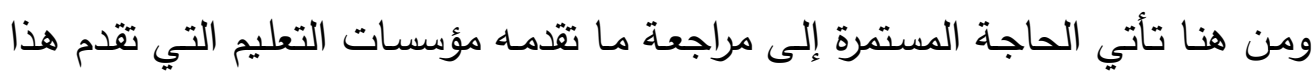

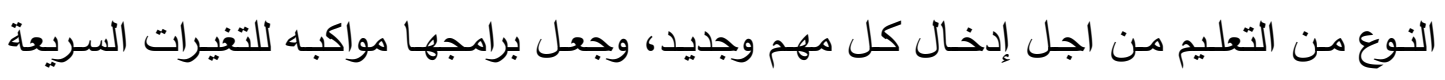
والمتلاحقة في التكنولوجيا وحاجة المتعلم والبيئة التي يعيش فئهن التيا.

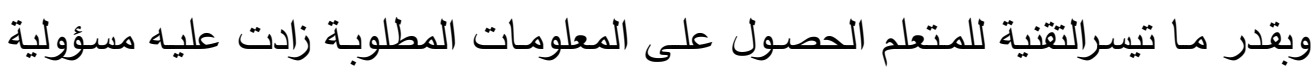

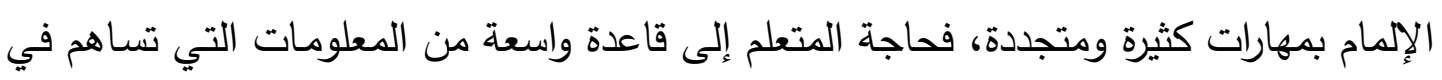
تعزيز التخصص أصبح ممكناً في الوقت الحاضر من خلاجل التعلم الاكتروني.

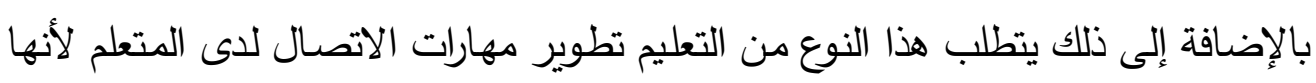

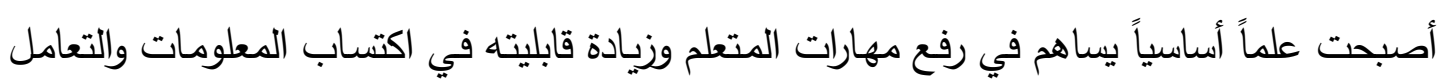
معها خلال دراسته وكذلك بعد نيله الثهادة من خلال برامج التعليم المستمر عبر الانترنت.

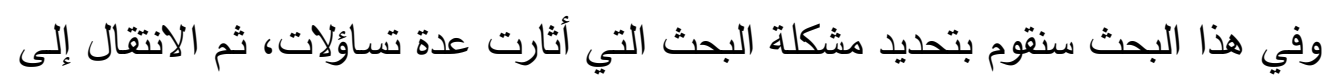
أهداف البحث وأهميته وحدوده، مرورا بعرض المستفيدين من البحث، مع ذكر أهم مصطلحاته.

\section{1/1}

إن مشكلة البحث الرئيسية والتي تعمل الدراسة علي بحثها والتغلب عليها تتلخص في

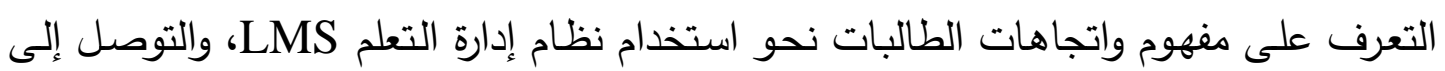
مدى التباين بين الطالبات المستخدمات للنظام وغير المستخدمات.

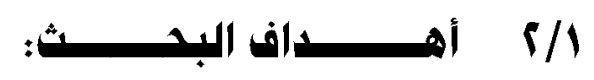

يهدف هذا البحث إلى توضيح مفهوم نظام إدارة التعلم LMS والتركيز على معرفة واقعه، وفهم الطالبات لذلك والتعرف على اتجاهاتهم نحو التعليم الالكتروني، وذلك من خـال

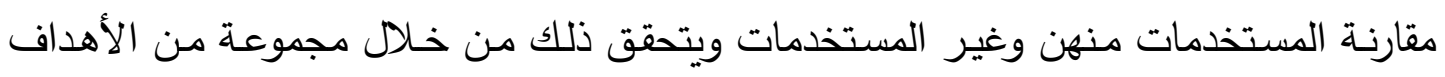
التفصيلية تتمثل في: التصنات " التعرف على مفهوم نظام إدارة التعلم LMS لاى الطالبات المستخدمات لهذا النظام. التعرف على مفهوم نظام إدارة التعلم LMS لدى الطالبات الغير المستخدمات لهذا النظام. التعرف على اتجاه الطالبات المستخدمات لنظام إدارة التعلم LMS نحو هذا النظام. 
" التعرف على اتجاه الطالبات الغير المستخدمات لنظام إدارة التعلم LMS نحو هذا النظام.

مدى التباين بين الطالبات المستخدمات لنظام إدارة التعلم LMS وغير المستخدمات

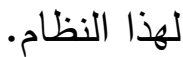

\section{: أسئل}

تسعى الاراسة إلى الإجابة عن الأسئلة التالية:

ما مفهوم نظام إدارة التعلم LMS لدى الطالبات المستخدمات لهذا النظام؟

ما مفهوم نظام إدارة التعلم LMS لدى الطالبات الغير المستخدمات لهذا النظام؟

ما هي اتجاه الطالبات المستخدمات لنظام إدارة التعلم LMS نحو هذا النظام؟

ما هي اتجاه الطالبات الغير المستخدمات لنظام إدارة التعلم LMS نحو هذا النظام؟ ما مدى التباين بين الطالبات المستخدمات لنظام إدارة التعلم LMS وغير المستخدمات

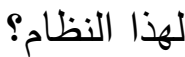

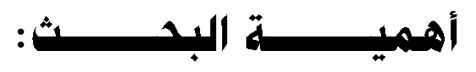

تتمثل أهمية البحث في أن نتائج هذه المقارنـة ستوضـح التباين في مفهوم واتجاهات

الطالبات نحو استخدام نظام ادارة التعلم LMS.

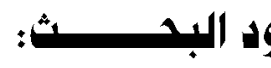

- الحدود الموضوعية: تمثلت في التعرف على مدى التباين بين الطالبات المستخدمات

لنظام إدارة التعلم LMS وغير المستخدمات لهذا النظام.

الحـدود البثـريةة: ستقتصـر الدراسـة على مجمـوعتين مـن طالبـات الدراسـات العليـا

$$
\text { (ماجستير) في كلية التربية بجامعة الملك سعود. }
$$

• الحدود المكانية: ستقتصر الدراسة على كلية التربية - جامعة الملك سعود.

الحدود الزمانية: تحددت خلال الفصل الدراسي الثاني للعام الدراسي ع إ هـ.

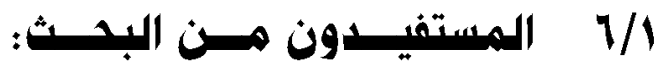

هالمؤولون في عمادة التعليم الإلكتروني والتعليم عن بعد في الجامعة. عمداء ووكلاء وأعضاء هيئة التدريس في الجامعة. 
أ.أماني العدواني، أ.نورة المجلي وراسة مقارنة في مفهو و واتجاهات التعلم الإلكتروني بين طالبات مرحلة الماجستير بكلية التربية

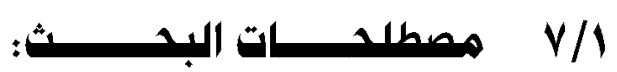

: Education التعلي_ا-1)

التعلم عملية تفكيريـة تنطوي على استخدام المعرفة السـابقة لدى المتعلم، واستراتيجيات تفكيرية خاصة لفهم الأفكار في الموقف التعليمي الجديد ومن ثم ربط المعرفة الجديدة بالمعرفة السابقة وإدماجها في البنية المعرفية للمتعلم، فهو تغير شبه دائم في الأداء يحدث نتيجة تأثير

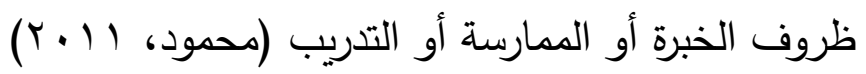

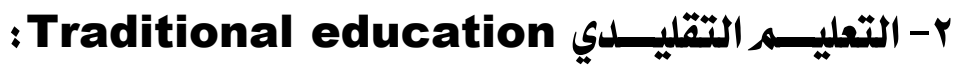

يعرف التعليم بأنها: عملية مقصسودة أو غير مقصسودة مخططة أو غير مخططسة تتم داخل المدرسة أو غير المدرسة في زمن محدد أو غير محدد ويقوم بها المعلم أو غير المعلم بقصد مساعدة الفرد على التعلم واكتساب الخبرات (السيد، ب ( ب r)

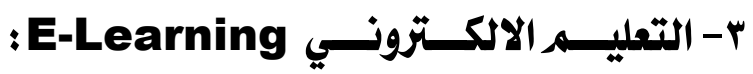
تعرفه الباحثتان على أنـا: طريقه للتعليم باستخدام آليات الاتصـال الحديثة كالحاسوب والثبكات والوسائط المتعددة من اجل إيصال المعلومة للمتعلمين بأسرع وقت وأقل كلفة وبصورة تمكن من إدارة العملية التعليمية وقياس وتقييم أداء المتعلمين. يُقِدم المحتوى التعليمي فيـه بوسـائط الكترونيـة مثل الانترنت أو الانترانت أو الأقمـار الصناعية أو الأقراص الليزرية أو الأشرطة السمعية/ البصرية.

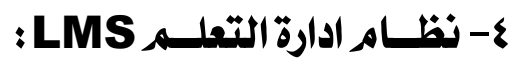

تعرفه الباحثتان على أنه: LMS هو اختصـار لعبارة Learning Management System إدارة ومتابعة وتقويم التدريب والتعليم المستمر وجميع أنشطة التعلم في المنشآت، لذا فهو يعتبر حل إستراتيجي للتخطيط والتدريب وإدارة جميع أوجه التعلم في المنشأة بما في ذلك البث الحي أو القاعات الافتراضية les classes virtuelles أو المقررات الموجهة من قبل المدربين، وهذا سيجعل الأنشطة التعليمية التي كانت منفصـلة ومعزولـة عن بعضـها تعمل وفق نظـام مترابط يسهم في رفع مستوى التدريب.

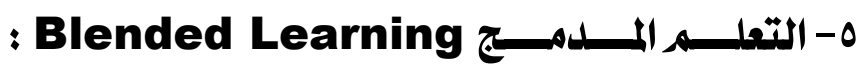

تعرفه الباحثتان على أنـه: هو إحدى صيخ التعليم أو التعلم التي يندمج فيها التعلم الالكتروني مع التعلم الصفي التقليدي في اطار واحد. 


\section{الإطـــار النظــــــي}

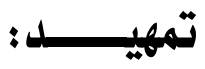

ثاني فصول البحث سيتناول محاور الإطار النظري، سنبدأ بالتعرف على مفهوم التعليم

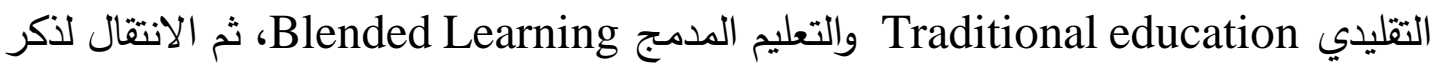
التعليم الجامعي المدمج Blended Learning، ثم الانتقال لذكر خصائص بيئة التعلم الدمدج Blended Learning وأخيراً سنعرض بعضاً من نتائج الدراسات السابقة.

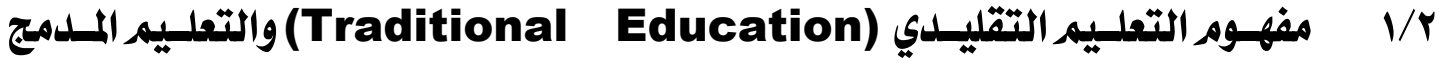

\section{: (Blended Learning)}

نظراً لاختلافات فى ترجمة مصطلح Blended Learning ظهرت مسميات عدة

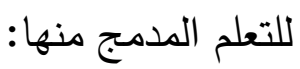

التعلم المدمج، والتعلم الخليط، والتعلم الممزوج، والتعلم الإكترونسى المدمج، والتعلك التكاك الهجين، والتعلم متعدد الدداخل، والتعلك المؤلف، وتجدر الإشارة إلى أن مفهوم التعلم المدمج يرتبط بعدة مصطلحات مثل: التعلم أون لاين Online Learning، والتعلم المعدل والمعد وفق التق التط

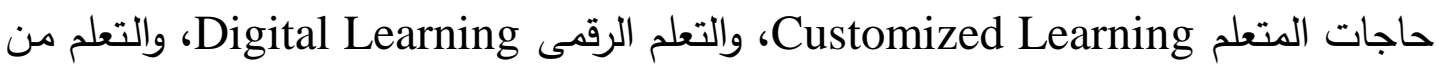

خلال الصفحات الإلكترونية Yapici\& AK Bayin، 2012) Plat Forms Learning ويعد التعليم الدماج Blended Learning مكملاً لأساليب التعليم التربوية العادية،

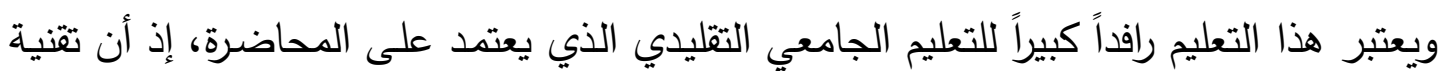

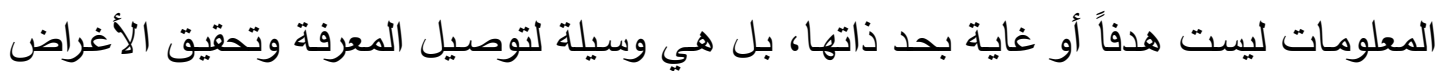

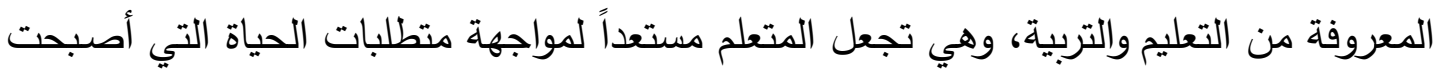

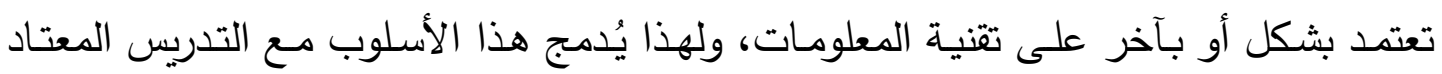

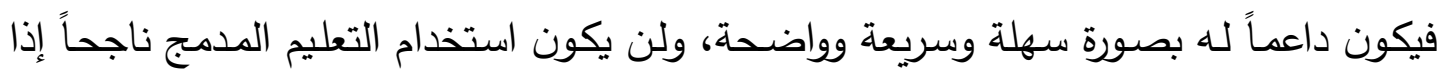

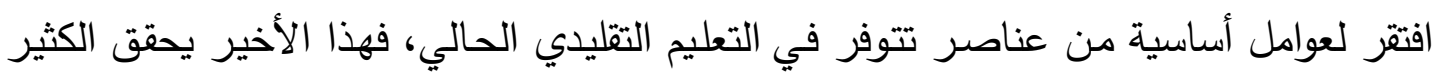

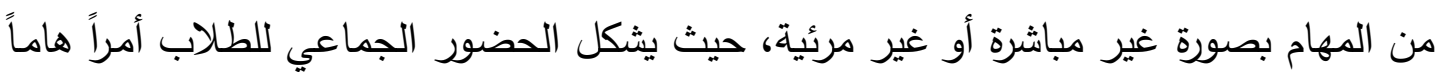

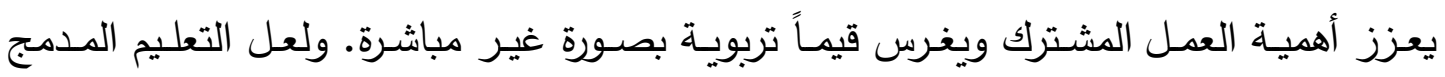
Blended Learning

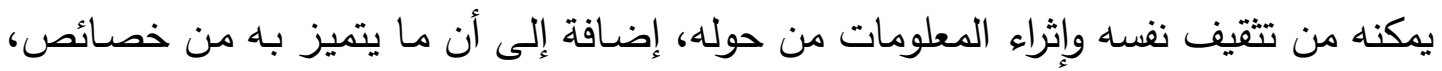
كمرونة الوقت وسهولة الاستعمال. 
ويرى عدد من التربويين والخبراء أن التعليم المدمجBlended Learning قد يلاقي

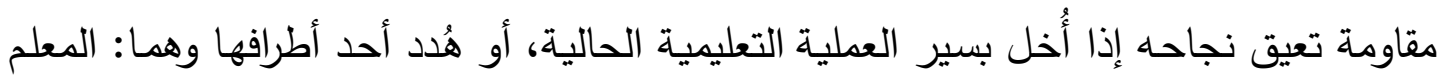
والمتعلم، فهما يمثلان المكونات الأساسية، إضافة إلى المناهج التعليمية والبرامج الإدارية، ولهذا لهائا

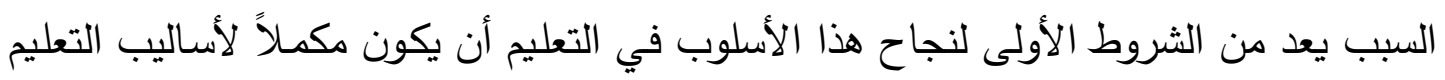

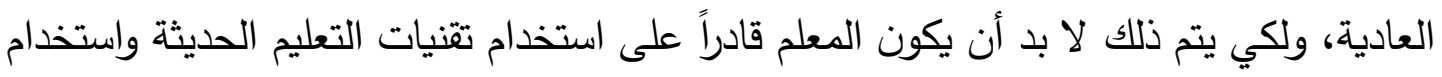

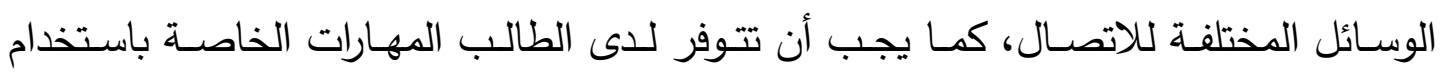

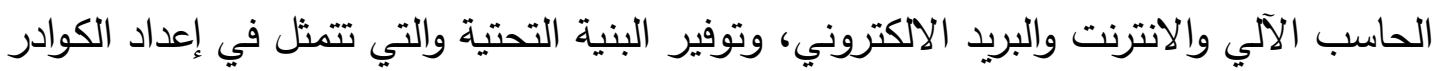

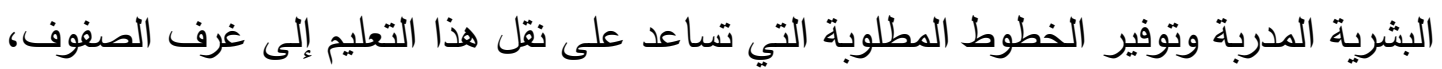
إضافة إلى توفير البرمجيات والأجهزة اللازمة لهذا النوع من التعليم.

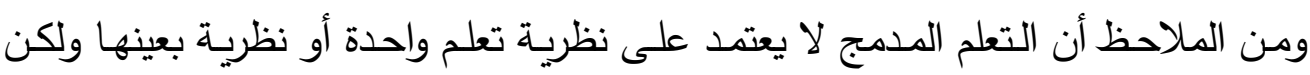

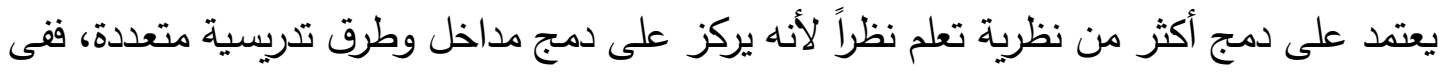

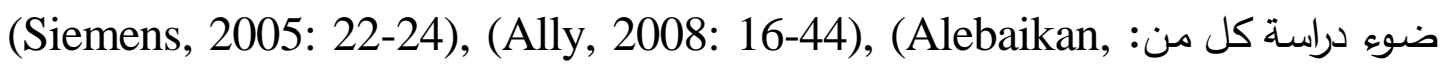
2010: 47-49), (AyGun, 2012: 25-28), (Saliba \& Cortez, 2013: 12-13) أهم النظريات الرئيسية للتعلم والتى يرتكز إليها التعلم المدمج تتمثل فى النظرية السلوكية، والتى تؤكد : التها على ملاحظة التغيرات فى سلوك المتعلمين، والنظريـة المعرفية: والتى تؤكد على تعزيز عمليات

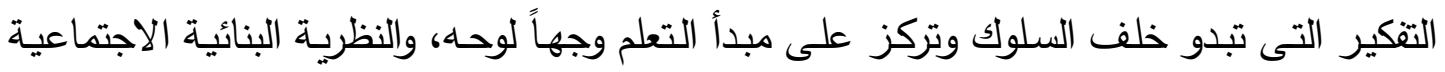

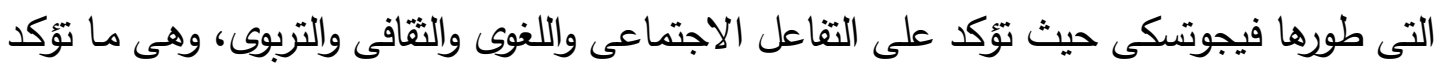
عليه استراتيجية التعلم المدمج التى تدعو إلى التفاعل بين الأنشطة الاجتماعية والمعرفية والنظرية

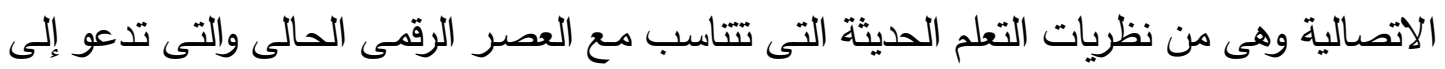

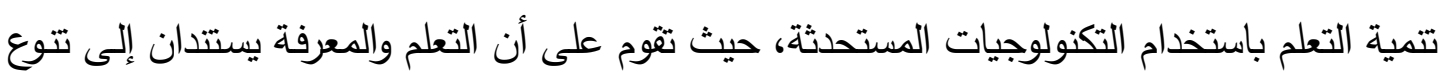
الأراء ووجهات النظر، وأن التعلم يقوم على عمليات التواصل اللفظى وغير اللفظى. إن النظر والتمعن في المفهوم الثـامل للتعليم المدمج Blended Learning يشير

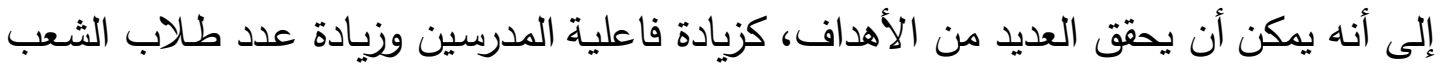

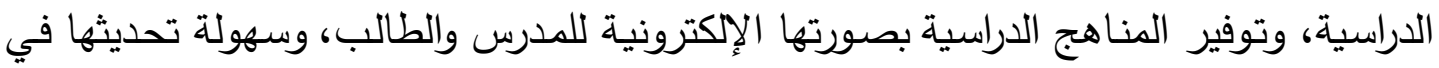

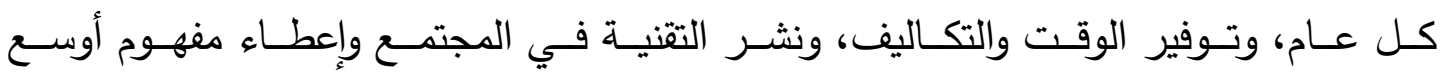

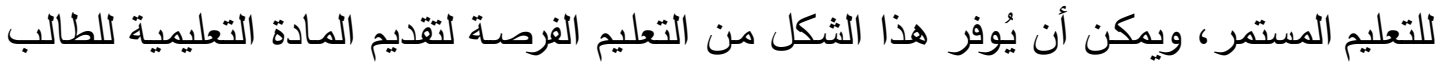
بصورة واضحة وإمكانية العودة إليها بسهولة. 


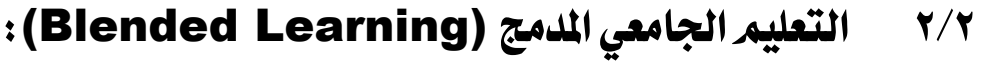

يبحث التربويون باستمرار عن أفضل الطرق والوسائل لتوفير بيئة تعليمية تفاعلية لجذب اهتمام الطلبة وحثهم على تبادل الآراء والخبرات، وتعتبر تقنية المعلومات ممثلة في الحاسب الآلي والإنترنت ومـا يلحق بهما من وسائط متعددة للاتصـال من أنجح الوسـائل لتوفير هذه البيئة التعليمية التي تعمل على تحقيق التكامل بين الجوانب النظرية والجوانب التطبيقية، وتتيح الفرصة لإكساب المتعلمين مهارات متقدمة في التفكير والتكامل في بناء المناهج الدراسية وربطها بالبيئة المحلية واحتياجات المجتمع، إضافة إلى دورها في مراعاة الفروق الفردية بين المتعلمين. ولهذا أصبح إتقان المهارات الأساسية اللازمة لاستخدام تقنية المعلومات من الضرورات الهامة في التعليم، لما لها من دور هام في تسهيل التواصل والحصول على المعلومات وإعداد

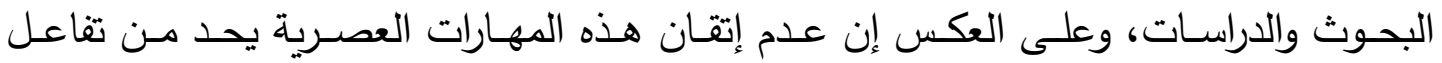
المدرسين مـع طلبتهم، والوصول إلى مصادر المعرفة الضرورية لعملية التدريس، فلقد أصبح استعمال الحاسوب وشبكة المعلومات الالكترونية من المتطلبات الرئيسية في عملية التدريس

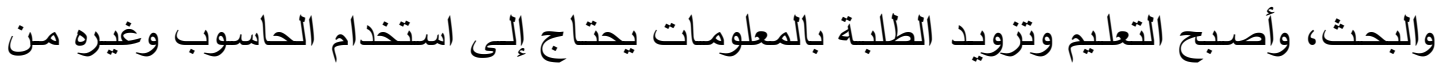

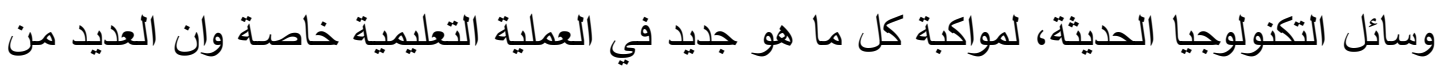
المصادر والمراجع والمعلومات أصبحت تخزن بصورة الكترونية، وأصبحت إمكانية العودة إليها واستخدامها تفرض معرفة ومهارة في استخدام التقنية الحديثة، إضـافة إلى ما توفره مثل هذه التقنية من سهولة وسرعة في الوصول إلى المعلومات.

ولهذا لم تعد مصادر المعرفة التقليدية كافية للحصول على المادة التعليمية بصورة كاملة، وأصبح من الضروري الاستعانة ببنوك المعلومات الحديثة التي تخزن معلوماتها بصورة الكترونية، وأصبحت القدرة في الوصول إلى هذه المصادر واستخدامها من العوامل التي تساهم في تطور التعليم وتتدمهـ وتحسين جودته، وأصبح من الضـروري أن يجيد المدرس والطالب في الجامعـة المهارات الضرورية التي تمكنهما من استخراج هذه المعلومات واستخدامها بصورة سهلة وسريعة. ويقصد بالتعليم الجامعي المدمج Blended Learning في هذا البحث استخدام التقنية الحديثة في التتريس دون التخلي عن الواقع التعليمي المعتاد ويتم التركيز على التناعل المباشر داخل غرفة الصف عن طريق استخدام آليات الاتصال الحيثة، كالحاسوب والثنبكات وبوابات الإنترنت. 
ويمكن وصف هذا التعليم بأنه الكيفية التي تُظظم بها المعلومات والمواقف والخبرات التزبوية

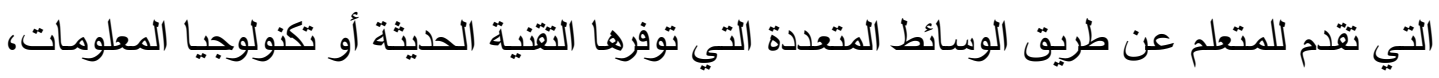
ويتميز هذا النـوع مـن التعليم باختصـار الوقت والجهـد والتكلفـة، مـن خـلال إيصـال المعلومـات للمتعلمين بأسـرع وقت وبصـورة تمكن مـن إدارة العمليـة التعليميـة وضـبطها، وقيـاس وتقيـيم أداء المتعلمين، إضافة إلى تحسين المستوى العام للتحصيل الدراسي وتوفير بيئة تعليمية جذابة. وإذا كانت المحاضرة هي إحدى طرائق التدريس المعتمدة على إلقاء المعلومـات، فان استخدام الوسـائط التقنية الأخرى بالاشتراك معها، يساعد في التخلص من المظاهر السلبية للتعليم التقليدي، الذي يعتمد على إلقاء المعلومة بالقراءة من قبل المحاضر ، إذ يجب أن يساعد التعليم على التفكير والإبداع والابتكار من خلال مشاركة فعالة بين المدرس والطالب، وتساعد الوسائط التقنية المستخدمة في إيصال المعلومات إذا استخدمت بالثكل المناسبفي خلق الأجواء التي تساعد على التفاعل والتفكير النقدي والمشاركة بين المدرس والطالب، ومن اجل استخدام الوسائط المتعددة في التعليم لابد أن يتوفر لدى المتعلم والمعلم المهارات الضرورية لاستخدام تكنولوجيا المعلومات.

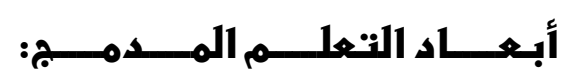

(Maguir, 2005: 22-24), (Kerres, 2003: 101-113), أشـار كل من

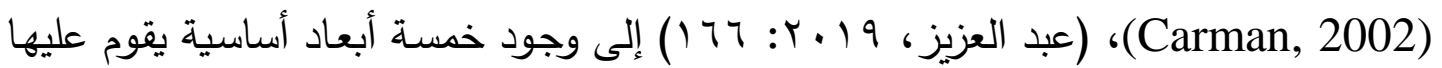

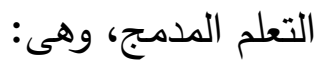

1- التعلم الذاتىى: وهو خبرات التعلم التـى يقوم بها المتعلم بنفسـه اعتمـادا على سرعته الخاصـة وزمنـه الخاص واحتياجاته وميوله، مثل التدريب باستخدام الأقراص المدمجـة والخول على المواقع الالكترونبة عبر الانترنت ذات الصلة بالموضوع. ץ- الأحداث الحية المتزامنة: وهى الأحداث التعليمية المتزامنة التى يقودها المعلم ويشترك فيها المعلم مـع المتعلمين فى نفس الوقت ونفس المكان فى حجرة الدراسـة التقليدية أو قاعة الدروس الافتراضية. ז- التعاون: وهى البيئات التى يتواصل فيها المتعلمون مـع بعضهم البعض أو مع المعلم عبر شبكة الانترنت وأمسا أن يكون التعاون بشكل متزامن مثل مثل غرف الدردشـة أو بشكل غير متزامن مثل البريد الأكترونى والمناقثات. 
ع- التقييم: وهو قياس معرفة ومهارات المتعلم ويمكن القيام بالتقييم القبلى قبل بداية برنامج التعلم المدمج، وذلك لتحديد المعرفة السابقة للمتعلم ويمكن القيام بالتققيم البنائى لتقييم المتعلمين فى كل خطوة من خطوات التعلم، والتفييم البعدى لقياس مدى تفدم التعلم. 0- مواد دعم الأداء: وهى المواد المرجعية المستخدمة فى المهمة لدعم تقدم التعلم وزيادة العائد التعليمى وبقاء أثر التعلم، وتتمثل فى المراجع والملخصـات المطبوعة والوسائل التعليمية المساعدة للمهمة.

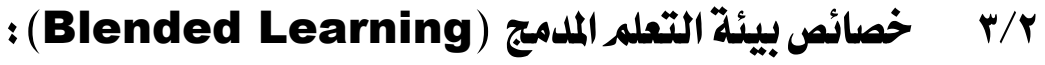

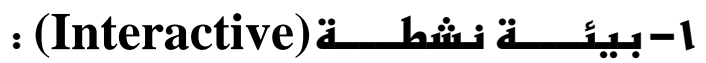

بمعنى أن المتعلم بإمكانه المشاركة في العملية التعليمية وأيضاً يعتبر هو المسؤول عن تعلمه والنتائج التي حصل عليها، وقد يستخدم البرامج التطبيقية لإجراء العمليات المنطقية أو الحسابية أو كأداة لإنتاج وعرض النتائج التي توصل إليها الطالب.

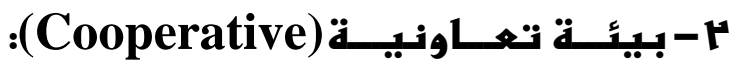
يمكن أن يعمل الطـلاب على شكل مجتمعـات تعلم صـغيره بحيث يسـاعد كـلاً مـنهم الآخر لتحقيق التعلم الأفضل، ويمكنهم استخدام برامج التعلم المختلفة لتعزيز التعلم التعاوني، ويمكن أن يستخدموا الشبكات الاجتماعية كأداة للاتصال فيما بينهم.

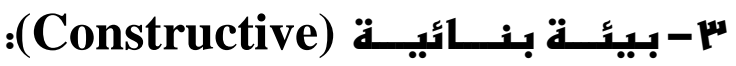

حيث يقوم الطـلاب بإدخال الأفكار الجديدة التي توصلوا إليها على المعرفـة السـابقة لديهم وذلك لتحقيق فهم أقوى للمعنى، ويمكنهم استخدام الحاسب الآلي في العمليات المعرفية والحسابية أو كأداة لعرض ما توصلوا إليه.

\section{ع- بئــة مقصـودة ومنـظمـة (Intentional)}

يكون لدى المتعلمين أهداف تعلمية يسعون إلى تحقيقها، وتساعدهم البرمجيات التعليمية المتنوعة (مثل برامج الممارسـة والتدريب وبرامج حل المشكلات وبرامج الدروس الخصوصية) في تحقق التعلم لدى الطلاب.

0-بئــة محـادنــة واتصـال (Conversational):

يُتاح للمتعلمين فرصة الانضمام إلى مجموعات تعاونية داخل قاعة الصف أو افتراضية باستخدام شبكة الإنترنت أو البريد الإككتروني مما يسهل من عملية التواصل بين المتعلمين وتبادل المعلومات والأفكار والنقاشات العلمية. 
أ.أماني العدواني، أ.نورة المجلي دراسة مقارنة في مفهو واتجاهات التعلم الإلكترونيي بين طالبات مرحلة الماجستير بكلية التربية

\section{1-بئـــة سيــاقيــة (Contextualized):}

تُقدم الواجبات والوظـائف للمتعلمين على شكل المشكلات من البيئة الحقيقة، ويمكن

استخدام برمجيات المحاكاة لمساعدة الطلاب على فهم وحل مثل تلك المشكلات.

\section{LMS}

بمراجعة التعريفات المختلفة لأنظمـة التعلم الالكترونى فاننـا نجد اتفاقا بين الباحثين

والعاملين فى هذا الجقل الالكترونى، وتعرف أنظمة ادارة التعلم الالكترنى Management Systems

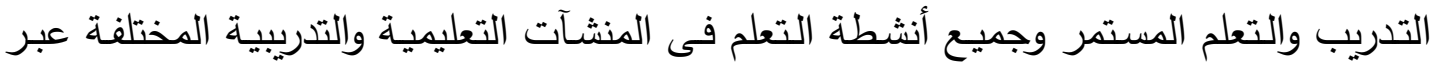

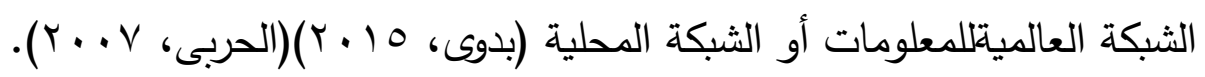

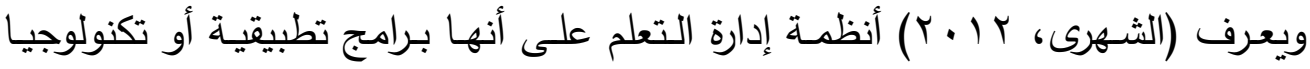
معتمدة على الانترنت تستخدم فى التخطيط وتتفيذ وتقويم عملية تعلم محددة، وعادة ما يزود

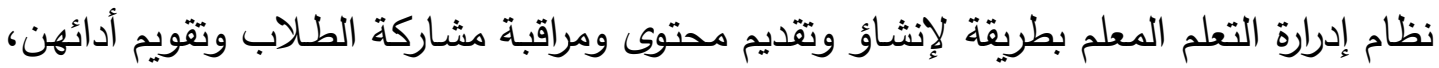

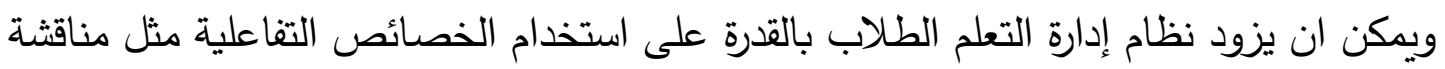
الموضوعات والاجتماعات المرئية ومنتديات النقاش وهى تعتمد على الثبكة العنكبوتية لتسهل عملية الوصول على محتويات وإدارة العملية التعليمية دون أى معوقات مكانية أو زمانية.

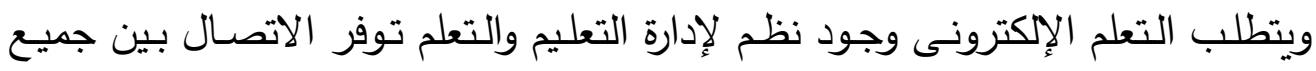

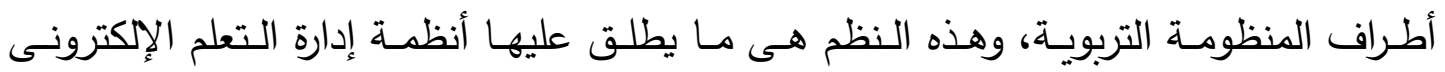
(LMS) Learning Management Systems الافتراضية وهى الانظمة التى تعمل كمساند ومعزز للعملية التعليمية بحيث يضع المدرس المواد

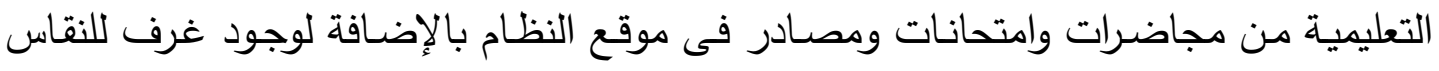

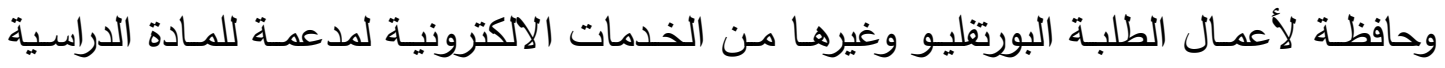

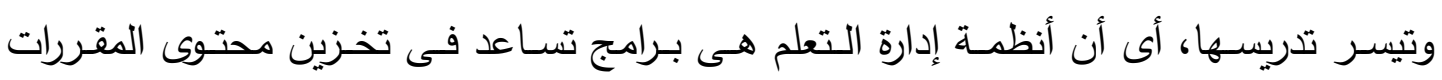

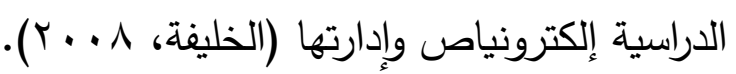

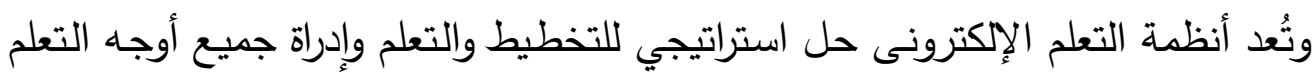

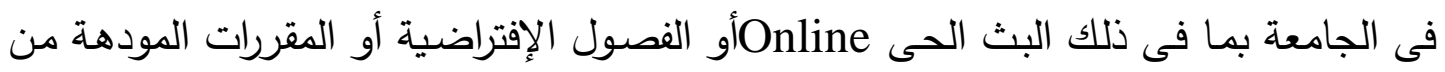

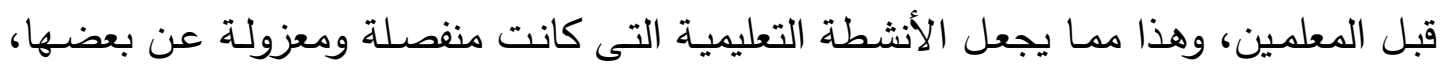

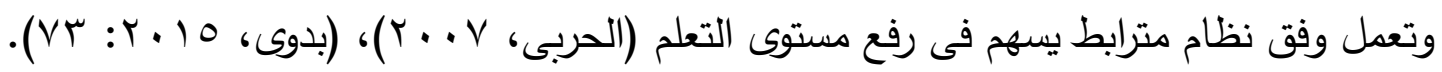




\section{$:$}

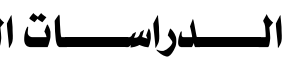

1- دراسة (عبد العزيز ، 9 ( ـ Y) التى هدفت الى تإجراء تحليل بعدى لبحوث التعلم المدمج

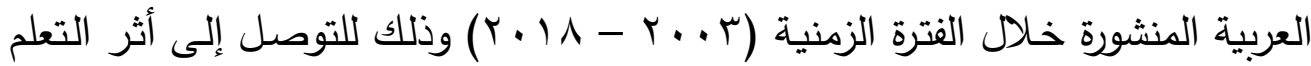

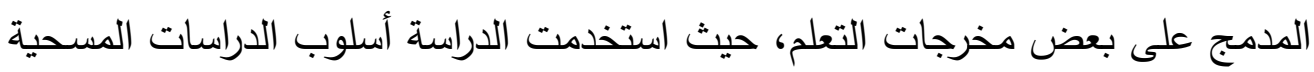

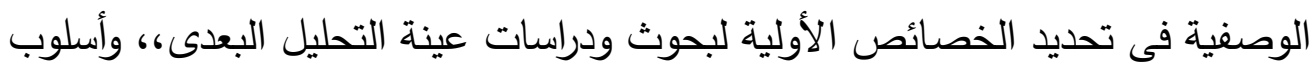
التحليل البعدى لتحليل نتائج البحوث والدراسات وتم تحليل VT من البحوث الكمية من رسائل الماجستير والدكتوراة والبحوث المنشورة بالدجلات والدوريات التربويـة المحكمة التحة

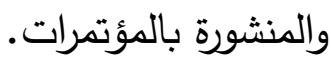

وأظهرت النتائج حسب مؤشر كوهن قيم كبيرة لمتوسط حجم الأثر للتعلم

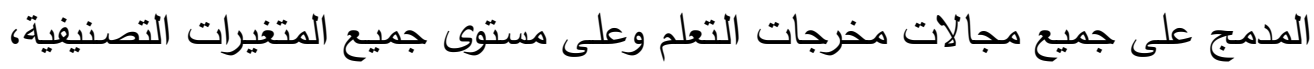

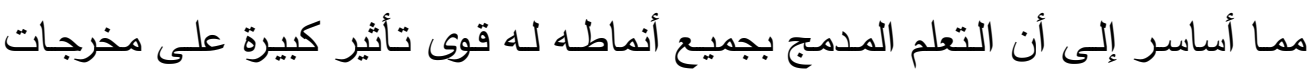

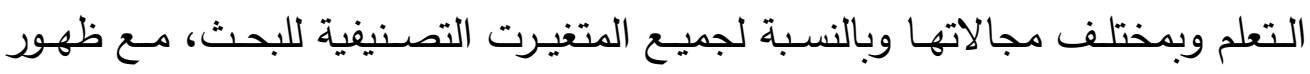
اختلاف فى درجة اهتمام الدراسات والبحوث السابقة بكل مجال من مجالات الجات مخرجات تعلم العلوم، وكذلك بكل متغير من المتغيرات التصنيفية.

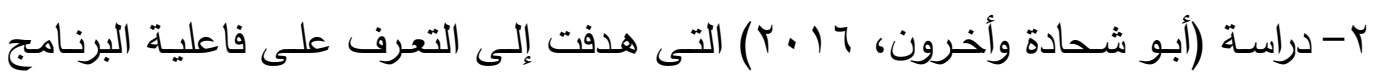

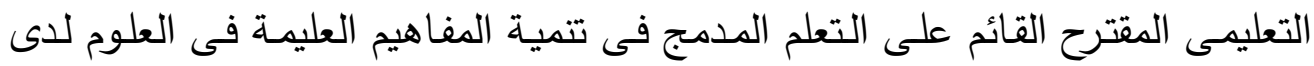

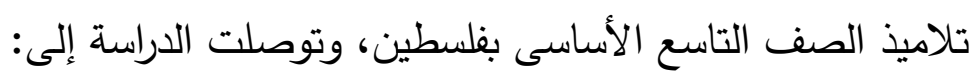

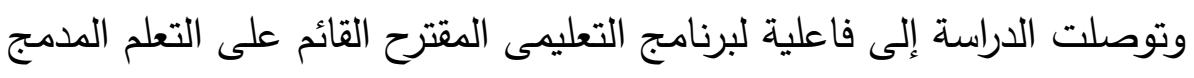
فى تتمية المفاهيم العليمة فى العلوم لدى تلاميذ العينة.

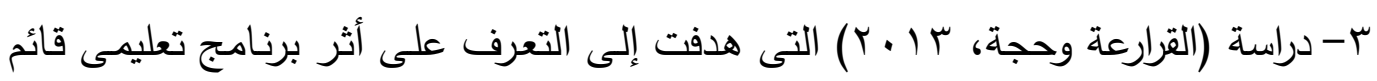

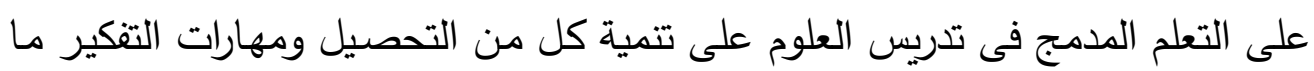
وراء المعرفى لدى طلاب العينة، وتوصلت الدراسة إلى: وجود فروق ذات دلالة إحصائية لثز البرنامج التعليمى فى تدريس التئس العلوم القائم على التعلم المدمج فى التحصيل وتتمية مهارات التنكير ما وراؤ المعرفى.

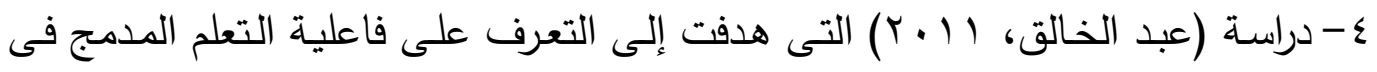
تتمية كل من التحصيل المعرفى والأداء المهارى للى طلاب العينة، وتوصلت الدراسة:

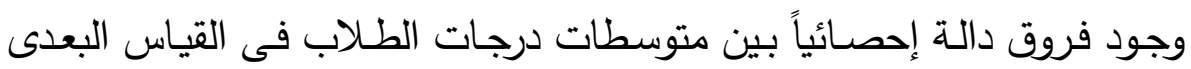

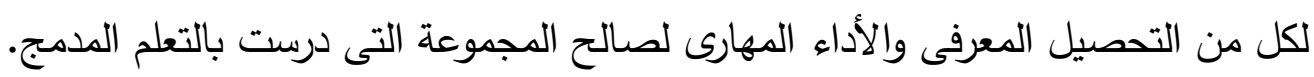




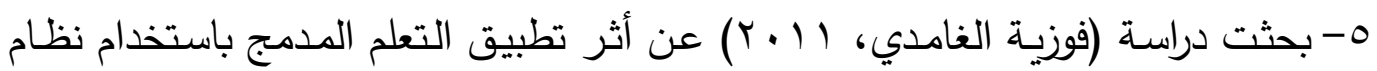
إدارة التعلم LMS على تحصيل طالبات مقرر إنتاج واستخدام الوسـائل التعليميـة بجامعة الملك سعود. وكانت عينة الاراسة شعبتين من شعب مقرر ( • هوسل) إنتاج واسـتخدام الوسـائل التعليميـة بكليـة التربيـة بجامعــة الملـك سـعود، والثـعبتين تمثل مجموعتي الدراسة التجريبية والضابطة، وتم تدريس المجموعة التجريبية باستخدام طريقة التعلم المـدمج وعددهم (YT) طالبـة، أمـا المجموعـة الضــابطة تم تدريسها بالطريقـة التقليدية وعددهم (YM) طالبة وتم تطبيق الدراسـة في الفصل الأول من العام الدراسي ه) $\leqslant T r / \mid \leqslant T$

\section{وتوصلت الدراسة إلى النتائج التالية:}

لا توجد فروق ذات دالة إحصائياً عند مستوى ( •، 0 . ) بين متوسطي درجات طالبات المجموعة التجربية والمجموعة الضابطة في الاختبار التحصيلي. توجد فروق ذات دالة إحصـائياً عند مستوى ( •، 0 .) بين متوسطي درجات طالبات المجموعـة التجريبيـة والمجموعـة الضـابطة في تقيـيم الأداء المهاري لمهارات تصـميم وتتفيذ الوسائل التعليمية لصالح المجموعة التجريبية والتي تعلمت بطريقة التعلم المدمج.

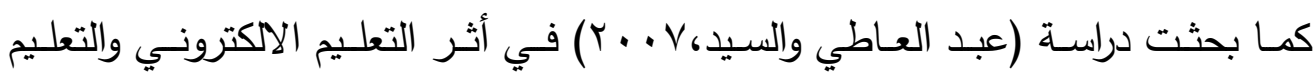
المدمج في تتمية المهارات والتصميم والإنتاج لمواقع الويب التعليمية لدى طلاب الدبلوم المهنية واتجاهاتهم نحو تكنولوجيا التعليم الاكتروني، وأجريـا دراستهم على عينـة عددها דr طالبا وطالبة قسموا إلى ثلاث مجموعات متساوية، مجموعتين تجريبيتين درست المجموعة التجريبية الأولى البرنامج عن طريق التعليم الالكتروني عبر الانترنت، ودرست المجموعة الثانية البرنامج عن طريق التعليم المدمج أما المجموعة الثالثة درست بالطريقة الطيقة التقليدية وقد استخدم اختبارات تحصيلية ومقياس أداء المهام ومهارات التصميم والإنتاج لمواقع الويب ومقياس اتجاه الطلاب نحو تكنولوجيا التعليم الاكتروني.

وقد خرج الباحثان بالنتائسج التالية: وجود فروق دالة إحصائيا بين متوسطات التحصيل الجانب المعرفي لمجموعة الطلاب الذين درسوا عن طريق التعليم التقليدي ومتوسطات التحصيل في الجانب المعرفي لمجوعة الطلاب الذين درسوا عن طرق التعليم الالكتروني لصالح التعليم التقليدي. 
عدم وجود فروق دالة إحصائيا بين متوسطات التحصيل في الجانب المعرفي لمجموعة الطلاب الذين درسوا عن طريق التعليم التقليدي ومتوسط التحصيل في الجانب المعرفي لمجوعة الطلاب الذين درسوا عن طريق التعليم المدمج.

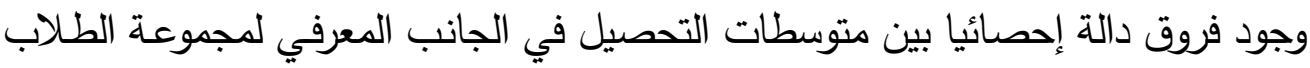
الذين درسوا عن طريق التعليم المدمج، ومتوسط درجات التحصيل في الجانب المعرفي، لمجموعة الطلاب الذين درسوا عن طريق التعليم الالكتروني، لصالح التعليم المدمج.

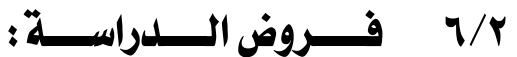

ا-وجود فروق ذات دلالة إحصائية بين الطالبات المستخدمات لنظام ادارة التعلم LMS

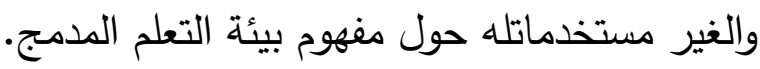
ب-وجود فروق ذات دلالة إحصائية بين الطالبات المستخدمات لنظام ادارة التعلم LMS والغير مستخدمات له حول اتجاهات استخدام بيئة التعلم الددمج. ז-وجود فروق ذات دلالة إحصـائية بين درجات الطالبات المستخدماتلنظام ادارة التعلم LMS في المواد التي تمت دراستها باستخدام التعليم التقليدي والتعلم المدمج.
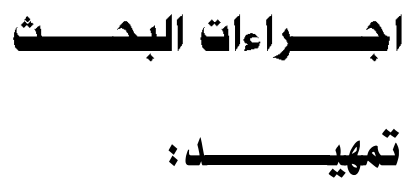

في هذا الفصل سنتناول اجراءات البحث وسيرها، ووضـع خطة مدروسة تبدأ بتحديد المجتمع وعينة البحث والأداة المستخدمة وتوضيح للمنهجية المختارة لهذا البحث.

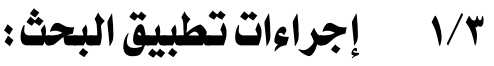

تتاول البحث في اطاره النظري بعض المعلومات التي توضح الدفاهيم المتعلقة بمفهوم التعليم التقليدي والتعليم المدمج، والتعليم الجامعي المدمج، وخصائص بيئة التعلم الددمج. تم البحث عبر الانترنت عن مفهوم التعليم الإلكتروني متمثلا في نمط التعليم المدمج

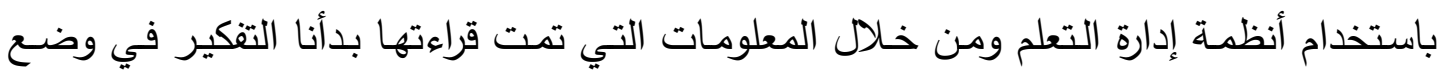
خطة مقترحة للبحث، حيثيسى هذا البحث الى عمل مقارنة بين الطالبات المستخدمات لنظام إدارة التعلم LMS والطالبات الغير مستخدمات لمعرفة مدى التباين في مفهوم التعلم المدمج 
Blended واتجاهات الطالبات نحو استخدام بيئة التعلم المدمج Blended Learning Learning من خلال تطبيق أسلوب المنهج الثبه تجريبي. كل ذلك تصفه الخطوات الاجرائية التي قامت بها الباحثتان طوال فترة اعداد البحث حتى ظهوره في صورته النهائية، وفقاً لما هو موضوع عبر تسلسل النقاط التالية:

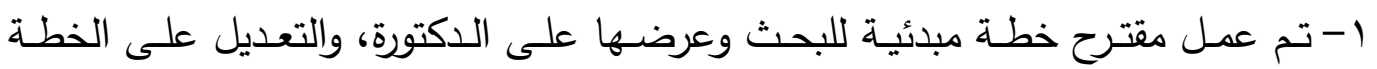
وكتابتها بشكل نهائي.

r- البدء في تجميع المحتوى النظري للبحث بعد تحديد المحاور الاساسية فيه.

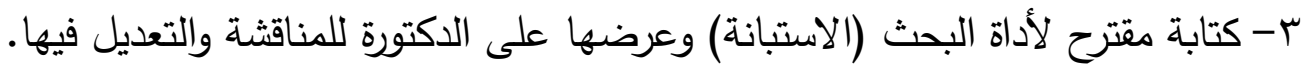

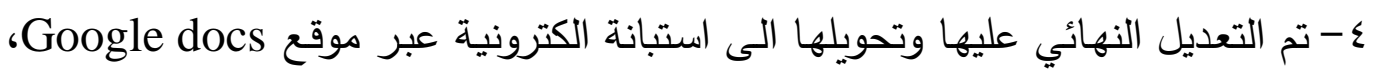
وإرسالها الى عينة البحث. ه- كأي نتاج علمي في مثل حجم وموضوع البحث لابد ان يواجه الباحث فيه عدة صعوبات نذكر منها على سبيل المثال: قلة تجاوب الطالبات في تعبئة أداة البحث (الاستبانة). 7- تم عمل تحليل احصائي لهحاور الاستبانة. V بعد جمع المعلومات وتحليل النتائج تم عمل مقارنة بين الطالبات المستخدمات لنظام إدارة التعلم LMS والطالبات الغير مستخدمات لمعرفة مدى التباين في مفهوم التعلم المدمج Blended Learning واتجاهات الطالبات نحو استخدام بيئة التعلم المدمج

.Blended Learning

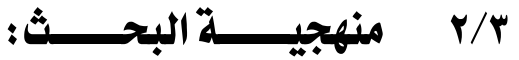

يتبع هذا البحث المنهج الثبه تجريبي، والذي يتمثل في هذا البحث في كيفية المقارنة

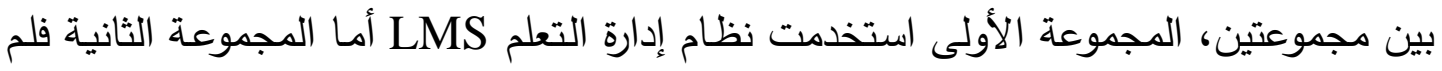

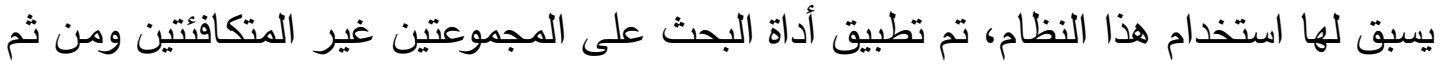
حساب النتائج، ويمكن القول إن المنهج المناسب للبحث الحالي هو المنهج الثبة التجريبي وذلك لملاءمته لطبيعة هذا البحث وأهدافه.

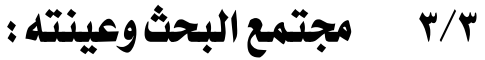

تمثل مجتمع البحث في طالبات الماجستير بكلية التربية بجامعة الملك سعود، أما عينة

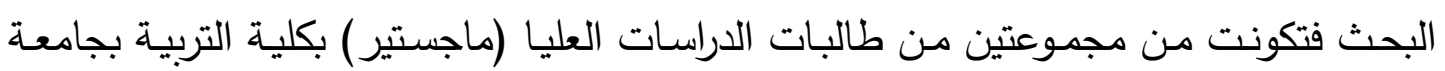


الملك سعود، بحيث تكون المجموعة الأولى قد استخدمت نظام إدارة التعلم LMS، وكانت هذه المجموعة من قسمي (مناهج وطرق تدريس الحاسب والإدارة التربويـة) وعددهم ^ب طالبة، أمـا المجموعة الثانية فلم يسبق لها التعامل مـ نظام إدارة التعلم LMS وكانت من قسمي (مناهج وطرق تدريس اللغة العربية والمناهج العامة) وعددهم ^ طالبات.

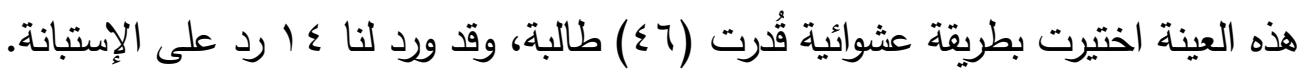
(

البحث الحالي يهدف الى التعرف على مفهوم واتجاهات الطالبات نحو نظام ادارة التعلم LMS لذلك يتعين علينا استخدام الإستبانة كأداة لهذا البحث، وهي من أفضل وسـائل جمع

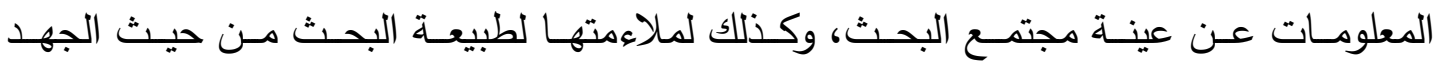
والإمكانيات، وقد روعي في هذه الأداة أن تشتمل على كافة الأسئلة والمتغيرات لموضوع البحث.

\section{بناء الاداةٌ/ قسمت هذه الاداة الى قسمين:}

يشتمل القسم الاول على البيانات الأولية لعينـة البحث كالخبرة في التعامل مـع نظـام ادارة التعلم LMS، وأيهما تفضلين التعليم الالكتروني أو التعليم التقليدي. أما القسم الثاني فيدور حول الأسئلة والمحاور الأساسية التي تحوي موضوع البحث وقد تكونت من ( • ع) فقرة موزعة على محورين وهما: مفهوم بيئة التعلم المدمج Blended Learning لدى الطالبات ( • ( م) فقرة. اتجاهات الطالبات نحو استخدام بيئة التعلم المدمج Blended Learning ( • ب) فقرة. وقد تبنت الباحثتان في اعدادهما للإستبانة الشكل المغلق الذي يحدد الاستجابات المحتملة لكل سؤال، حيث كانت الإستجابات على النحو التالي :أوافق بشدة، أوافق، محايد، أعارض، أعارض بشدة

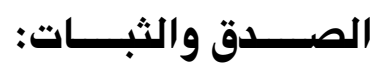

تم عرض الاستبانة بصورتها الأولية على الدكتورة [نورة الهزاني] المشرفة على البحث حيث أبدت رأيها حول مدى وضوح الفقرات ودرجة ارتباطها بكل بعد من أبعاد الاستبانة، هذا بالإضـافة إلى وضسوح صياغتها، وفي ضوء الملاحظات التي تم الاتفاق عليها اتضـح صـلاحية الاستبانة لقياس ماوضعت لقياسه، ثم أخذت الإستبانة شكلها النهائي وطبقت على عينة البحث. 
أ.أماني العدواني، أ.نورة المجلي دراسة مقارنة في مفهو و واتجاهاتا التعلم الإلكترونيي بين طالبات مرحلة الماجستير بكلية التربية

النتــائــــج والتــوصيــات

في آخر فصول هذا البحث سيتم تحليل للنتائج ومناقشتها لإبراز أهم تلك النتائج التي تم

الوصول إليها بعد مقارنة المجموعتين مع عرض مجموعة من التوصيات.

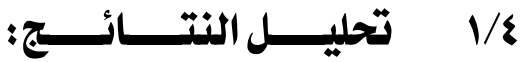

أولا: تصليل نتائج البيانات الأولية:

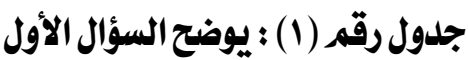

\begin{tabular}{|c|c|c|}
\hline \multicolumn{3}{|c|}{ سل ا هل لديك مكرة عن نظام إدارة التعلد Ims } \\
\hline$\%$ OV & $\wedge$ & نهم \\
\hline$\%$ & 7 & $y$ \\
\hline
\end{tabular}

نتيجة السؤال الأول

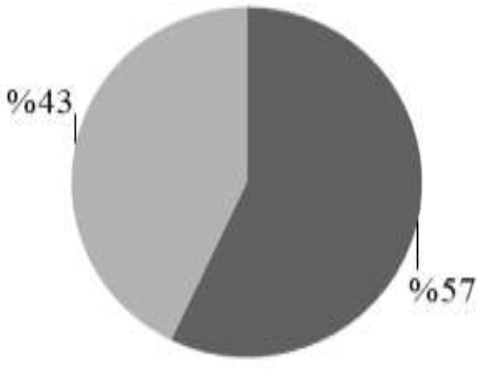

نعم

ㄴ.

شكل رقم (1) : يوضح نتيجة السؤال الأول

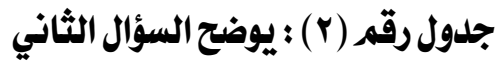

\begin{tabular}{|c|c|c|}
\hline \multicolumn{3}{|c|}{ س Ims Im : هل خبرتك في استخلدام نظام إدارة التعله } \\
\hline$\%$ & 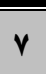 & أقل منسنة \\
\hline$\%$ & 1 & 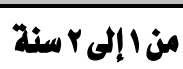 \\
\hline$\%$ & - & أكثر من سنتين \\
\hline$\%$ \% & 7 & ل اخبرة للاي \\
\hline
\end{tabular}




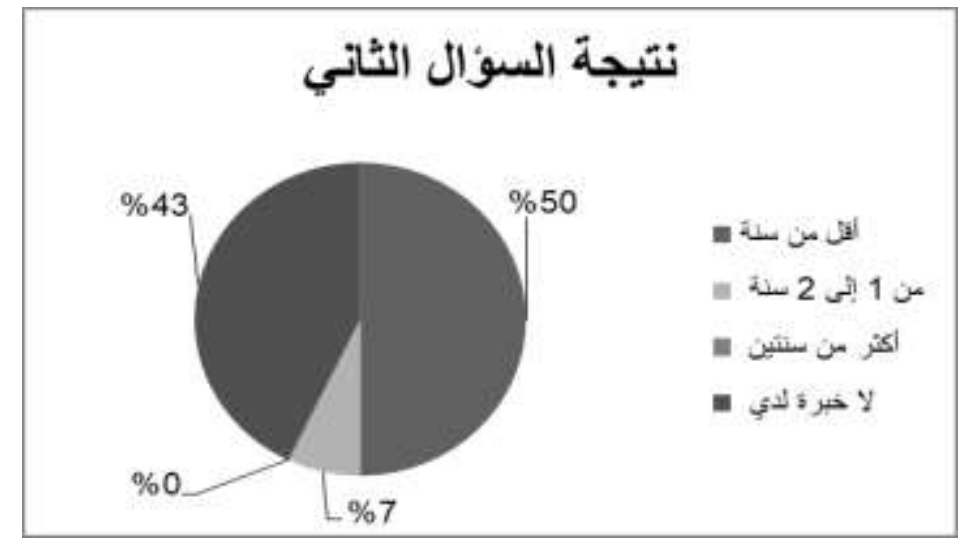

شكل رقم (r) : يوضح نتيجة السؤال الثاني

جلدول رقم (r) : يوضح السؤال الثالث

\begin{tabular}{|c|c|c|}
\hline \multicolumn{3}{|c|}{ 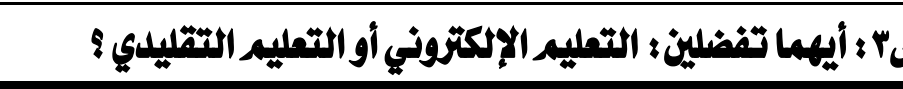 } \\
\hline$\% r$ & $r$ & التمليم الإككتوني \\
\hline$\%$ & - & التعليم التقليلي \\
\hline$\% \vee q$ & 11 & ألضشهle \\
\hline
\end{tabular}

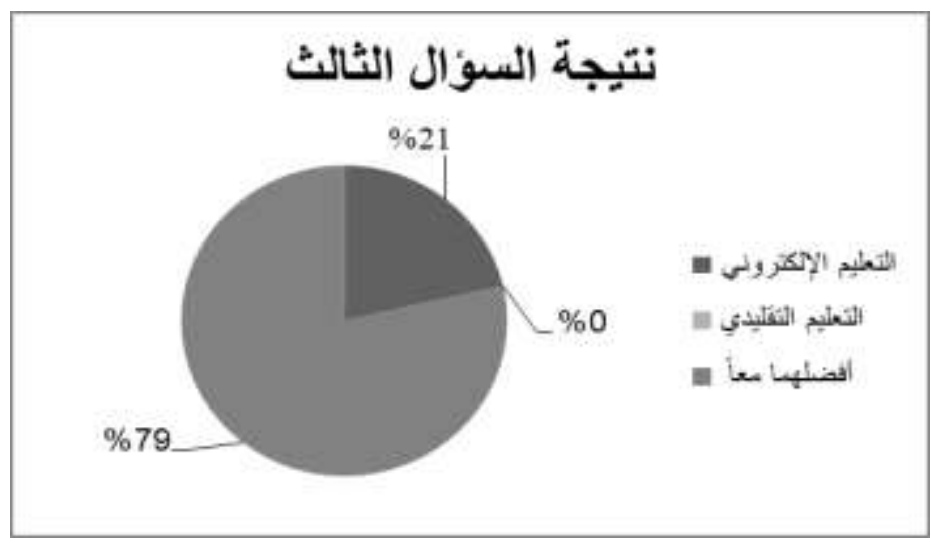

شكل رقم (r) : يوضح نتيجة السؤال الثالث

جلول رقم (؟) : يوضح السؤال الرابع

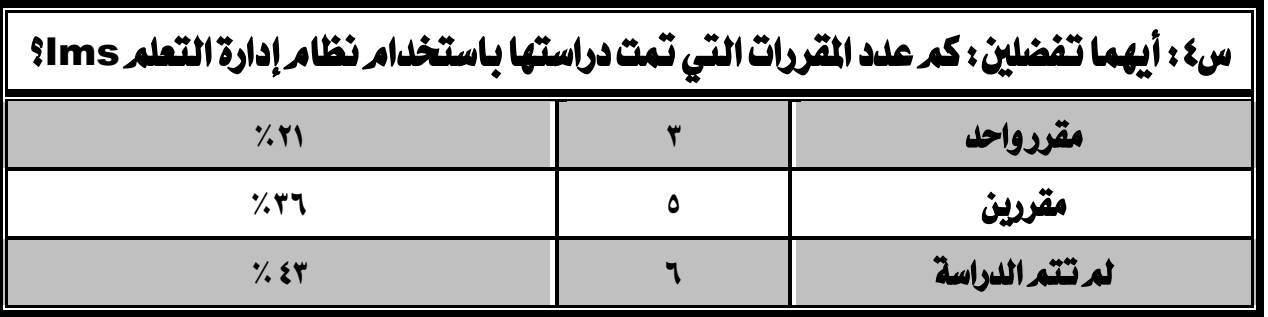


أ.أماني العدواني، أ.نورة المجلي دراسة مقارنة في مفهو و واتجاهاتا التعلم الإلكترونيي بين طالبات مرحلة الماجستير بكلية التربية

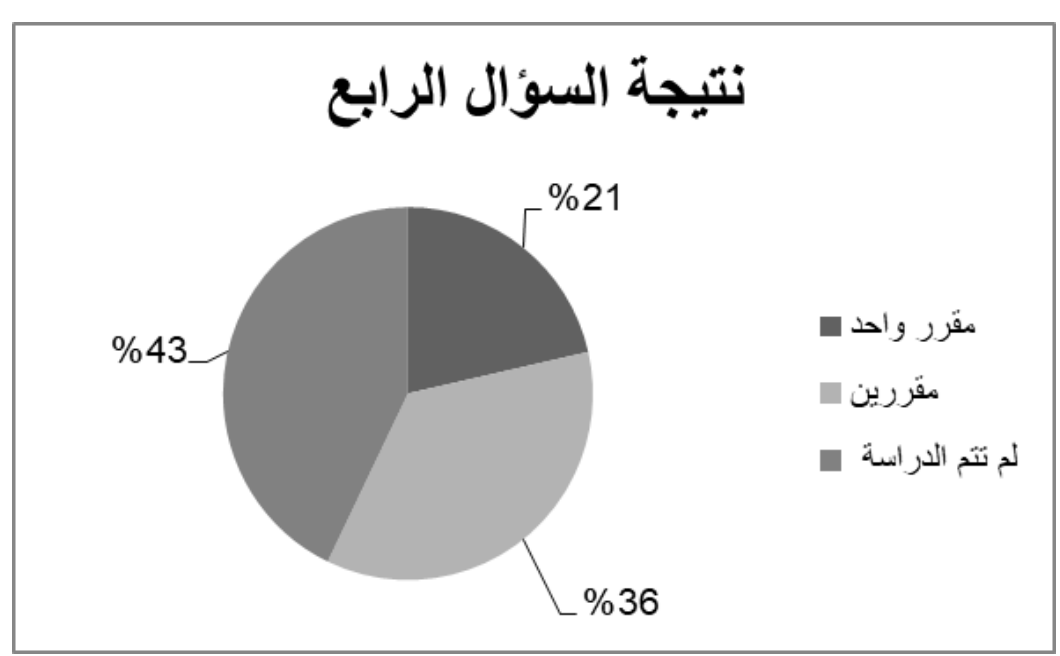

شكل رقم (§) : يوضح نتيجة السؤال الرابع

ثانيا: تصليل نتائج البيانات الأساسية:

المحور الأول: مفهوم بيئة التعلم المدمج blended learning لدى الطالبات أ) الطالبات الفير مستخدمات لنظام إدارة التعلم Ims:

جلول رقم (0) : يوضح المحور الأول / مفهوم بيئة التعلم المدمج لدى الطالبات الفير مستخلمات

\begin{tabular}{|c|c|c|c|c|c|c|}
\hline المجموع & أعارض بشدة & أعارض & محايل & أوافق & أوافق بشدة & تقييه المحور \\
\hline ir. & $r$ & 7 & $r \Lambda$ & 07 & 11 & التكرار \\
\hline$\% 1$. & $\% 7,1$ & $\% 0$ & $\% r,, Y$ & $\%\{\neg, \vee$ & $\% 10$ & النسية \\
\hline
\end{tabular}

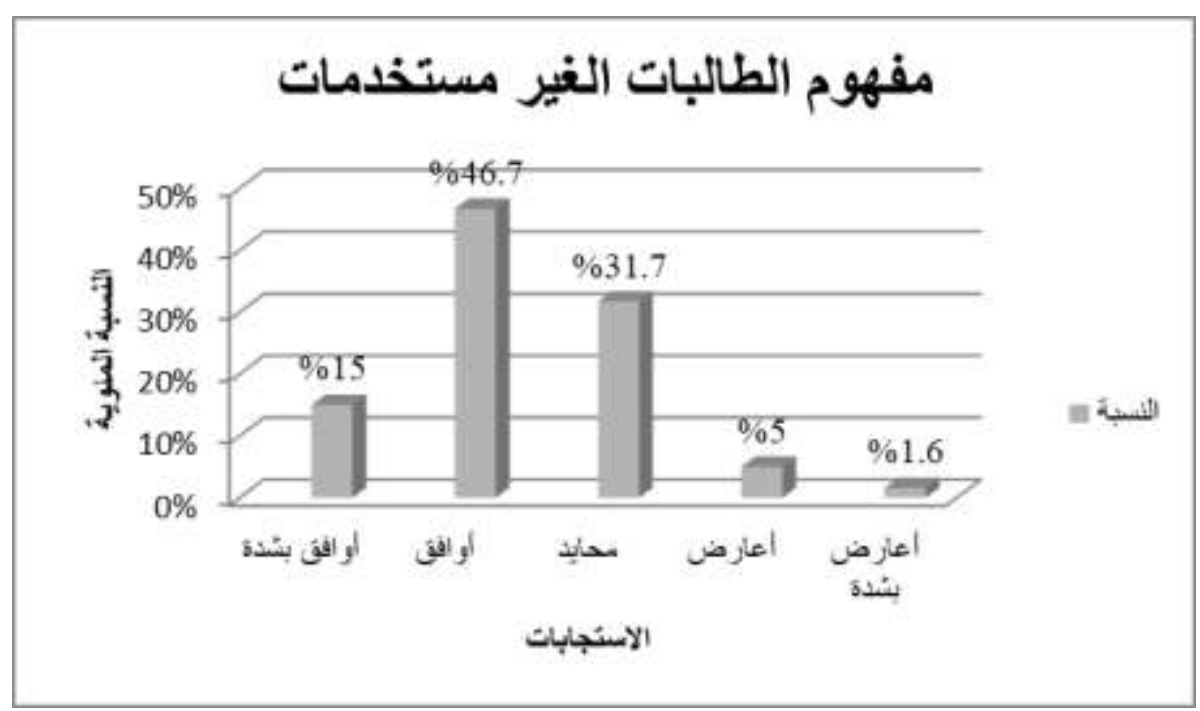

شكل رقه (0) : يوضح النسبة لنتائج المحورا : مفهور بيئة التعلم الملدجج للى الطالبات الفير مستخلمات 
ــ ـــلال الرسـم السـابق يتضـح لنـا توزيـع الطالبـات الغير مستخدمات لنظـام إدارة التعلم بحسب مفهوم بيئة التعلم المدمج، حيث تبين ان أعلى نسبة V, ا I \% لديهم خلفية عن مفهوم بيئة التعلم المدمج، وقد كانت اقل نسبة 7,7\% 7 لا يوجد لديهم خلفية عن مفهوم بيئة التعلم المدمج، اما المحايدون فقد بلغوا نسبة V, اس \% . ب) الطالبات المستخدمات لنظام إدارة التعلم Ims: جدول رقم ( ) ) يوضح المحور الأول / مفهوم بيئة التعلم المدمج للى الطالبات المستخدمات

\begin{tabular}{|c|c|c|c|c|c|c|}
\hline المجموع & أعارض بشلة & أعارض & محايل & أوافق & أواقق بشلة & تقيييم المحور \\
\hline 17. & - & 10 & $r V$ & $7 \varepsilon$ & $\Delta \xi$ & التكرار \\
\hline $1 .$. & - & $\%$ १,६ & $\% 17,9$ & $\% \varepsilon$ & $\% r r, r$ & النسبة \\
\hline
\end{tabular}

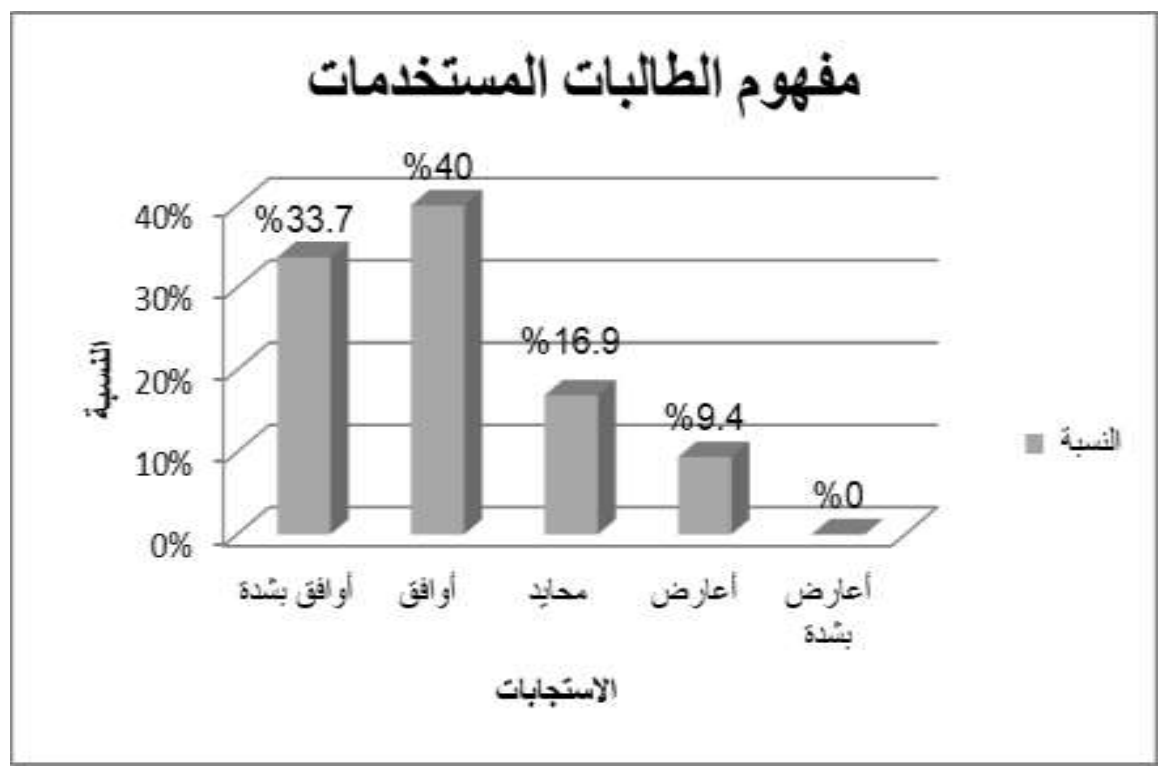

شكل رقم ( ) : يوضح النسبة لنتائج المحورا : مفهوم بيئة التعلم الملدمج للدى الطالبات الفير مستخلمات

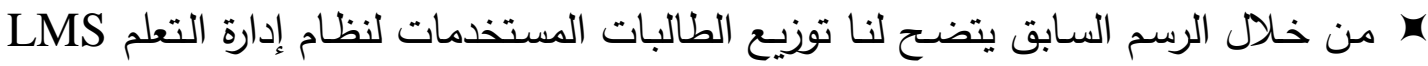
بحسب مفهوم بيئة التعلم المدمج، حيث تبين ان أعلى نسبة VVr,V\% لديهم خلفية عن مفهوم بيئة التعلم المدمج، وقد كانت اقل نسبة ع,9\% \% لا يوجد لديهم خلفية عن مفهوم بيئة التعلم المدمج، اما المحايدون فقد بلغوا نسبة 9,7 1 \% 
أ.أماني العدواني، أ.نورة المجلي دراسة مقارنة في مفهو و واتجاهاتا التعلم الإلكترونيي بين طالبات مرحلة الماجستير بكلية التربية

المحور الثاني: اتجاهات الطالبات نحو استخدام بيئة التعلم المدمج blended learning : أ) الطالبات الفير مستخدمات لنظام إدارة التعلم Ims:

جلول رقم (V) : يوضح المحور الثاني / اتجاهات الطالبات الفير مستخدمات لبيئة التعلم المدمج

\begin{tabular}{|c|c|c|c|c|c|c|}
\hline المجموع & أعارض بشدة & أعارض & محايد & أوافق & أوافق بشدة & تقييم المحور \\
\hline ir. & 1 & $\varepsilon$ & ro & $7 r$ & 11 & التكرار \\
\hline$\% 1 \cdots$ & $\cdot, \wedge \%$ & $\% r, r$ & $\% r q, r$ & $\% 01, Y$ & $\% 10$ & النسبة \\
\hline
\end{tabular}

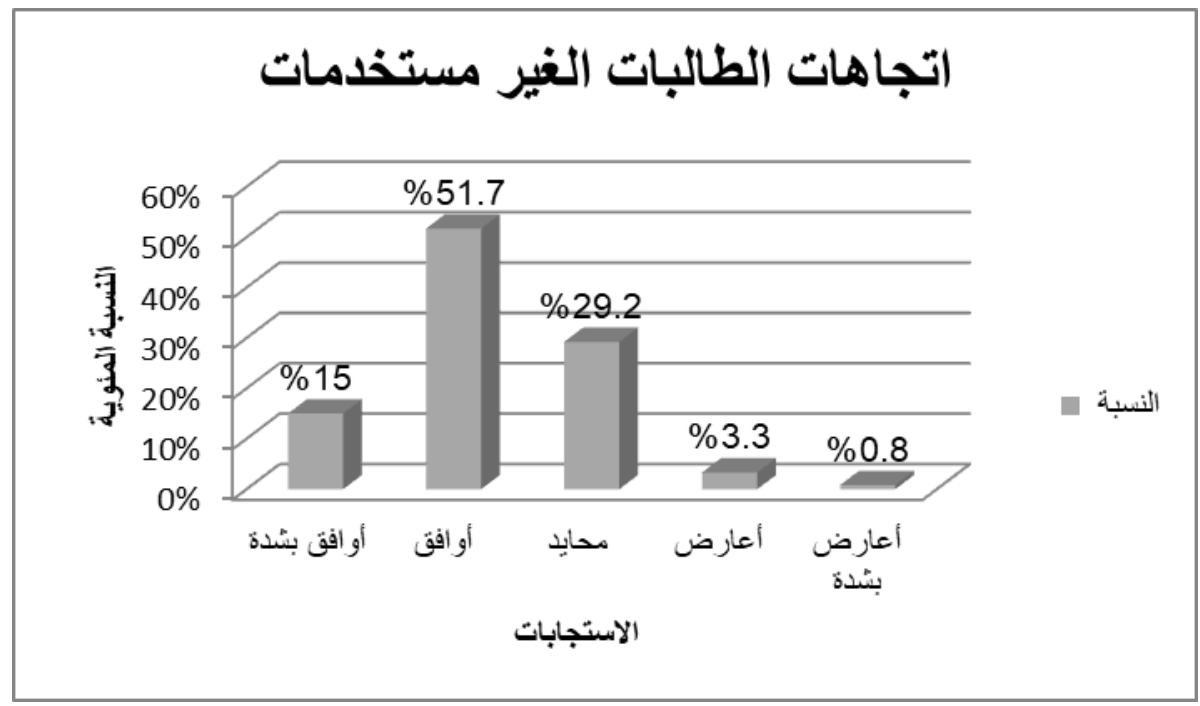

شكل رقم (Y) : يوضح النسبة لنتائج المحورץ : اتجاهات الطالبات الفير مستخدمات لبيئة التعلم الملدمج

LMS من خلال الرسم السابق يتضح لنا توزيع الطالبات الغير مستخدمات لنظام إدارة التعلم

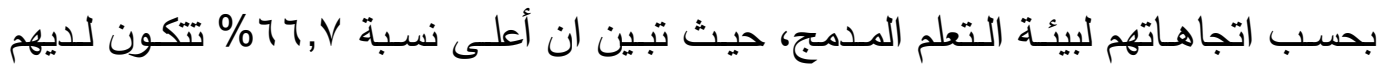
اتجاهات إيجابية نحو استخدام بيئة التعلم المدمج، وقد كانت اقل نسبة ا, ؛\% لا تتكون لديهخ اتجاهات نحو استخدام بيئة التعلم المدمج، اما المحايدون فقد بلغوا نسبة ؟ ب r \% . ب) الطالبات المستخدمات لنظام إدارة التعلم Ims؛ جلول رقمـ ( A) : يوضح المحور الثاني / اتجاهات الطالبات المستخلمات لبيئة التعلم الملدمج

\begin{tabular}{|c|c|c|c|c|c|c|}
\hline المجموع & أعارض بشلة & أعارض & محايل & أواثق & أوافق بشلة & تقيييم المحور \\
\hline 17. & 1 & $\Lambda$ & IV & vq & $\Delta 0$ & التكرار \\
\hline$\% 1 \ldots$ & $\% 1,7$ & $\%$ & $\% 1,, 7$ & $\%$ \%१, ₹ & $\% r \varepsilon, \xi$ & النسبة \\
\hline
\end{tabular}




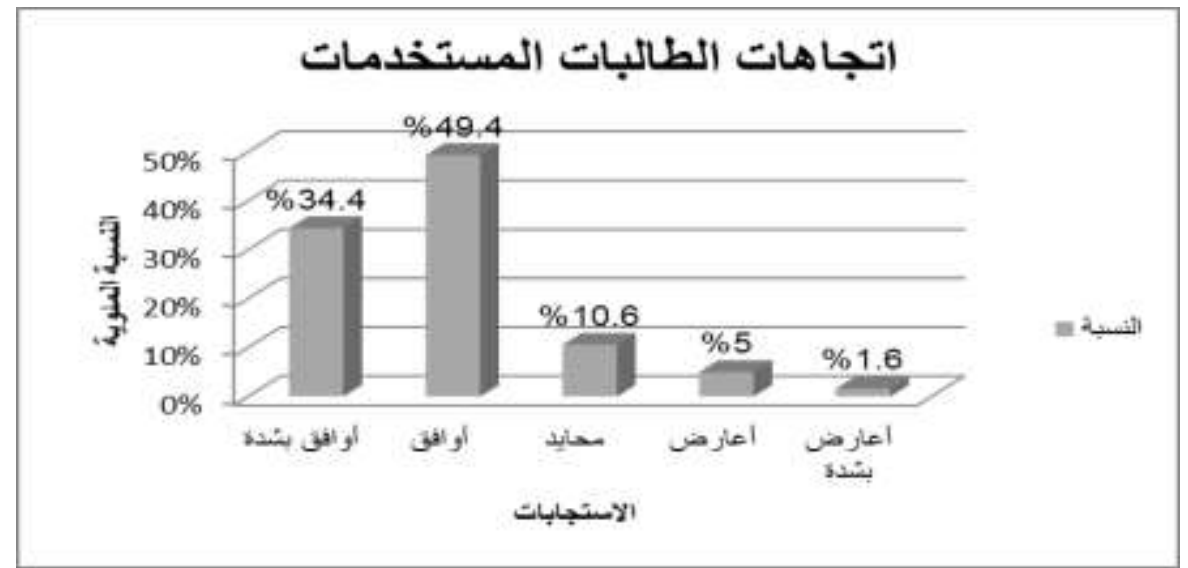

شكل رقهم (^) : يوضح النسبة لنتائج المحور ؛ اتجاهات الطالبات المستخلمات لبيئة التعلم الملدمج

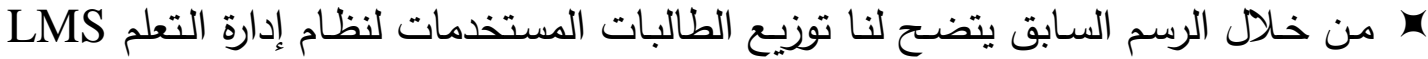
بحسب اتجاهـاتهم لبيئة التعلم المدمج، حيث تبين ان أعلى نسبة ^,؟^\% تتكون لديهم

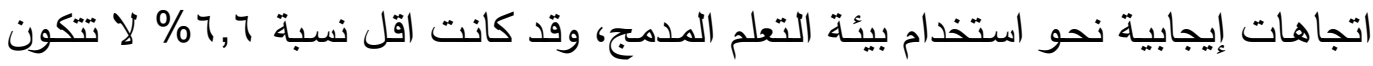
لديهم اتجاهات نحو استخدام بيئة التعلم المدمج، اما المحايدون فقد بلغوا نسبة ج, • (\%). r/\& بعد استعراض نتائج الدراسـة تـم رفض الفرض الأول والثاني، وقبـول الفرض الثالث للدراسة، والوصول للنتائج التالية: بالنسبة لنتيجة الفرض الأول: يمكن تفسير عدم وجود تباين في مفهوم بيئة التعلم المدمج بين الطالبات المستخدمات لنظام إدارة التعلم LMS والطالبات الغير مستخدمات، وذلك لأننا نعيش في عصر يحتم علينا استخدام التقنية بأنواعها في التعليم ودمجها مع التعليم التقليدي، لذا تكونت لاى المجموعتين خلفية لا بأس بها حول مفهوم بيئة التعلم المدمج. توصلت الدراسـة إلى عدم وجود تباين واضـح حول اتجاهـات الاستخدام لبيئة التعلم المدمج لدى المجموعتين، وذلك لرغبـة المجموعـة الغير مستخدمة لنظـام إدارة التعلم LMS بنـاء على رأي الطالبـات المستخدمات لنظـام إدارة التعلم LMS فإنـه يوجد فرق في التحصيل بين المواد التي تمت دراستها باستخدام التعليم المدمج والتعليم التقليدي لصالح التعليم التقليدي، حيث أن أغلب الطالبات حصلن على درجات أعلى في المقرر الذي تم دراسته باستخدام التعليم التقليدي. 


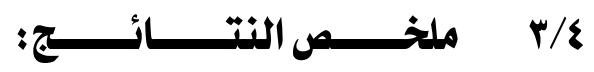

نلاحظ من خلال نتائج الإستبانة تفاوت في الاستجابات مابين الطالبات المستخدمات

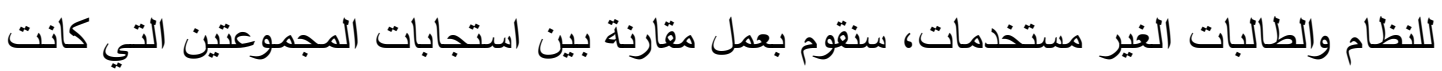
حول محاور الإستبانة والمتمثلة في محورين هما:

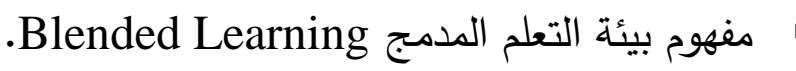

• اتجاهات الطالبات نحو استخدام بيئة التعلم المدمج Blended Learning.

$$
\text { وذلك لتوضيح أوجه الثبه والاختلاف ما بين المجموعتين. }
$$

\section{أولاً: أوجه 1الاتفاق بيز استجابات المجمو عتيزن:}

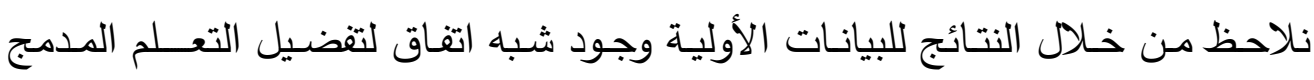
Blended Learning الاقتصار على أحدهما في التعلم.

نلاحظ أن . . 1\% من استجابات المجموعتين يرون أن الطالبة تجد في بيئة التعلم

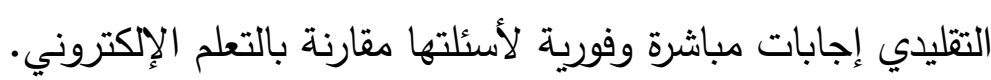

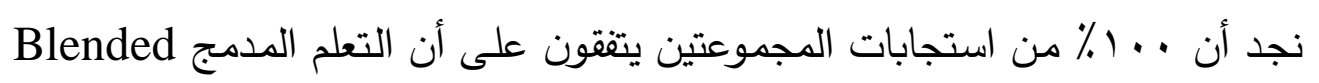

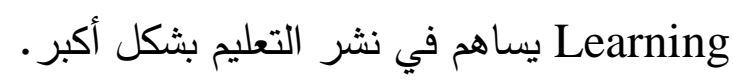
نلاحظ أن هناك اتفاق تام بنسبة . . 1 ٪ بين استجابات المجموعتين حول استخدام المكتبة الرقمية وفائدتها في البحث التي تعتبر من أهم الخدمات المقدمة في نظام إدارة التعلم LMS. هناك اتفاق كلي بنسبة . . 1 ؛ يرون أن التعلم الدممج Blended Learning مساند ومعزز لعملية التعليمية.

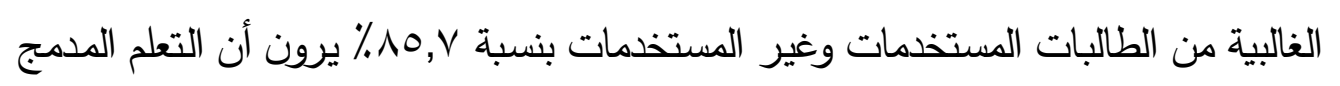
Blended Learning التقنية وحث الطالبات على استخدامها في حل الواجبات والأبحاث الخاصة بمقراراتهر.

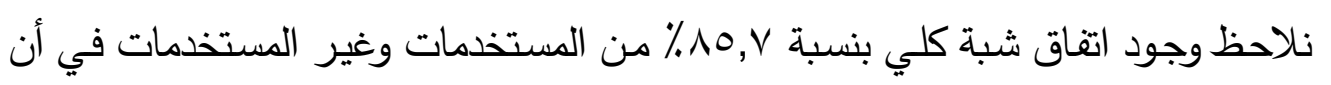
هيمنة اللغة الإنجليزية قد ساهم في الحد من نمو التعلم الالكتروني في المجتمع العربي. 


\section{ثنانباً: أوجه 1لاهنتافْ بين استنجابات المجمو عتبنز:}

• أغلب الطالبات المستخدمات لنظام إدارة التعلم LMS كانوا لا يرون أن التعلم المدمج Blended Learning الغير مستخدمات للنظام فيتوقعون أن التعلم المدمج Blended Learning سيزيد من تعلم الطالبة. أغلـب الطالبـات المســخدمات لنظـام إدارة الـتعلم LMS يـرون أن الـتعلم المـدمج Blended Learning وسيلة جيدة للتواصل مـع أعضـاء هيئة التدريس، أما بالنسبة للطالبـات الغير مسـخدمات فنـرى تفـاوت في اسـتجاباتهن فـالبعض يؤيدـ ذلك والبقيـة يعارضون لصالح التواصل المباشر • نلاحظ وجود شبه اتفاق بين المستخدمات لنظام إدارة التعلم LMS والطالبات الغير مستخدمات في أن التعلم المدمج Blended Learning يجعل عمليـة التعلم أكثر كفاءة وسرعة. نلاحظ من خلال النتائج حول توفر التعلم المدمج Blended Learning للطالبة عند الحاجة أن الطالبات المستخدمات لنظام إدارة التعلم LMS فالغالبية منهم بنسبة 0, ب ٪

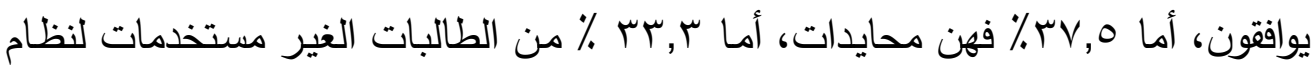
إدارة التعلم LMS يرون ذلك، أما الغالبية فهم محايدون وقد يعود ذلك إلى صعوبة توفر الانترنت أو بطء الاتصال أي ما يتعلق بالبنية التحتية للتعلم الاككتروني. نلاحظ من خلال النتائج أن الطالبات المستخدمات لنظام إدارة التعلم LMS بنسبة Ov,O يعارضون وجود صـوبة في تطبيق أسـاليب التقويم فهم يرون إمكانية تطبيق من خـلال

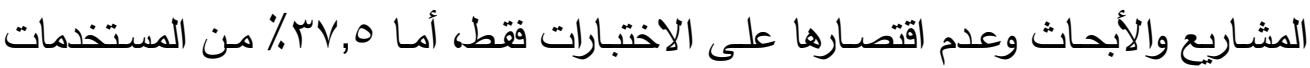
محايدات والبقية بنسبة هץ \% فهم يوافقون على وجود صعوبة في تطبيق أساليب التقويم في التعلم المـدمج Blended Learning، أمـا بنسـبة .0 ٪ ٪ مـن الطالبـات الغيـر 
مستخدمات لنظام إدارة التعلم LMS يوافقون على أنه يوجد صسوبة في تطبيق أساليب التقويم في التعلم المدمج Blended Learning بينما ـ% المتبقيات فهن محايدات. نلاحظ أن الطالبات المستخدمات لنظام إدارة التعلم LMS فالغالبية منهم بنسبة ه, ب ٪ يتققون أن التعلم الالكتروني يركز على الجانب المهاري دون الجانب الوجداني، أيضـاً ץ, ب^٪ من الطالبات الغير مستخدمات لنظام إدارة التعلم LMS يرون ذلك.

\section{ל/}

أمسام هذا المـد الالكتروني، وثورته المعلوماتية، وتأثيراته الحاليـة والمستقبلية وخاصـة في

الميادين التربوية والتعليمية، وفي ظل ما جاء في ادبيات البحث، توصي الباحثتان بما يلي: ا- تأكيـد ضـرورة الاهتمـام مـن قبـل الجامعـات بإدخـال أسـلوب التعلـيم الإلكترونـي

بنمط التعليم المدمج.

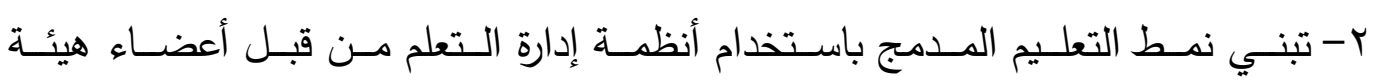

$$
\text { التدريس والطلبات. }
$$

r-تدريب الطالبات على استخدام أنظمة إدارة التعلم نظرا لما توفره من أدوات مساعدة في

عملية التعليم.

ع - عقد دورات تدرببية لأعضاء هيئة التدريس لتدريبهم على استخدام أنظمة إدارة التعلم.

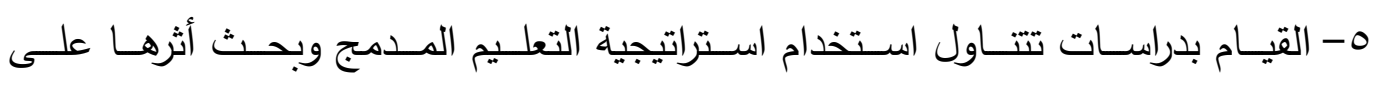

$$
\text { متغيرات أخرى. }
$$

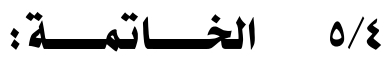

إن الغرض من التعليم هو إيصـال المادة والخبرة العلمية والمعرفية في مجالات مختلفة

إلى المتلقي (الطالب) وهذه العملية تحتاج إلى بيئة وعوامل خارجيـة وداخليـة وأدوات مختلفـة لتحقيق هذا الغرض، فإذا بدأنا بالتعليم التقليدي وهو أقدم أنواع التعليم فأنسه يحتاج إلى بيئة 
لتطبيق عملية التعليم والى أدوات مساعدة لإيصـال المـادة إلى طالبيها. وهو بذلك يحتاج إلى توفر الزمان والدكان والأدوات العلمية لتحقيقه.

وبمرور الوقت وتطور الحياة وتوفر الوسائل العلمية الحديثة أصبح بألأمكن تطبيق

التعليم ولكن باستخدام وسـائل حديثة لإيصـال المـادة العلميـة إلى طالبيهـا ذات كفاءة عاليـة وسرعة، فهي بذلك توفر وتقلل من كلفة المادة والوقت وتعطي مرونة أكثر في التعامل المتبادل

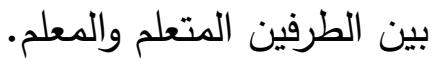

ولذلك لابد من المسارعة في تطبيق اساليب التعلم الدديثة والعمل على توفير البيئة

المناسبة لتطبيقها مع الاهتمام بزيادة نشر الوعي لاى اعضاء هيئة التدريس والطلاب لضمان تطبيق هذه الاساليب على الوجة الصحيح. 


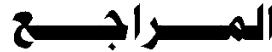

1 - أبو شحادة، كفاية حسين شوباش، وآخروون (7 ( • Y)، فاعلية برنامج مقترح قائم على التعلم المدمج فى تتمية المفاهيم العلمة لدى تلاميذ المرحلة الأساسية العليا فى فلسطين، مجلة

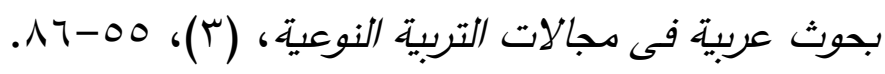

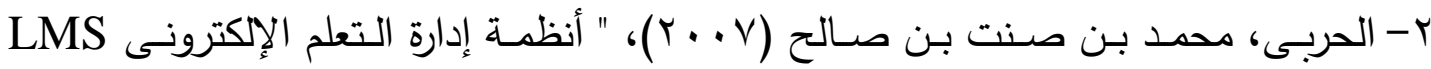
ودورها فى تفعيل الإتصال فى العملية التربوية والتعليمية"ورقة عمل مقدمة للقاء الثانى عشر للإثراف التربوى بمنطقة تبوك r ا-ــ ا مايو، الرياض. ץ- الخليفة، هند بنت سليمان (^ . ㄷ)، "من نظم إدارة التعلم الإلكترونى" ورقة مقدمة للمؤتمر الدولى الاول للتعلم الإلكترونى والتعليم عن بعد، 7 ا-1 (مـارس، الريـاض، وزارة التعليم

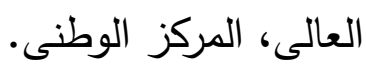

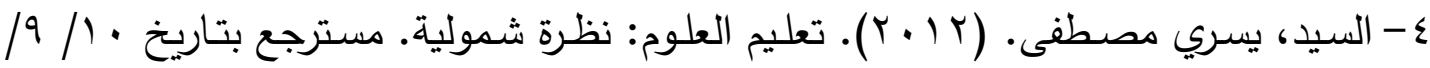
r 1 • r على الرابط http://www.khayma.com/yousry/Science\%20Teaching\%20for\%20Be ginners\%20Lect\%203.htm

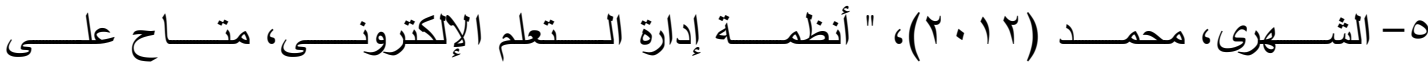

\section{post.htmlhttp://mohd211.blogspot.com/1Q31/31/blog-}

צ- الغامدي، فوزية (11 + rم )، "أثر تطبيق التعلم المدمج باستخدام نظام إدارة التعلم بلاكبورد على تحصيل طالبات مقرر إنتاج واستخدام الوسائل التعليمية بجامعة الملك سعود"، رسالة ماجستير ، جامعة الملك سعود، كلية التربية، قسم تقنيات التعليم.

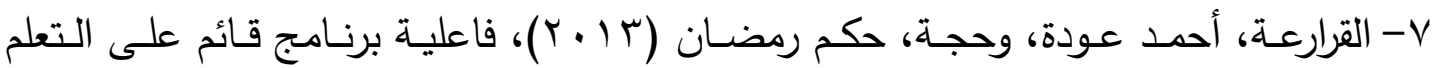
الدمجج فى تدريس العلوم فى تحصيل طلبة الصف التاسع الأساسى وتنمية مهارات التفكير

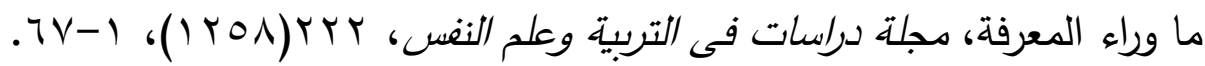




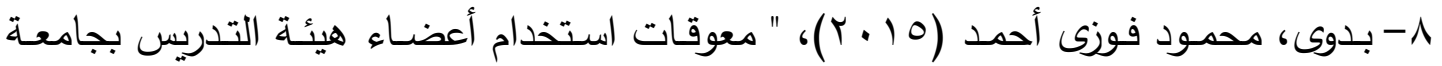
المنوفية لأنظمة إدارة التعلم الأكترونى LMS من وجهة نظرهم" مجلة كلية التربية، جامعة

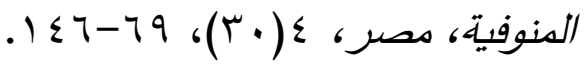
9- عبد الخـالق، دعاء صـبحى (1 (1 ب)، فاعلية التعلم المدمج فى تتميـة مهارات التصـيم التعليمى لدى طلاب تكنولوجيا التعليم بكلية التربية التوعية، رسالة ماجستير، كلية التربية التوعية: جامعة نبها.

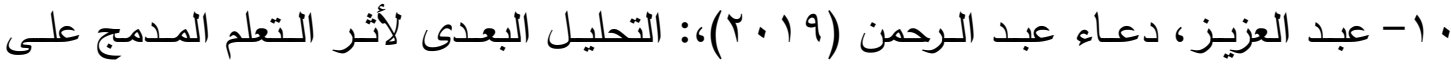

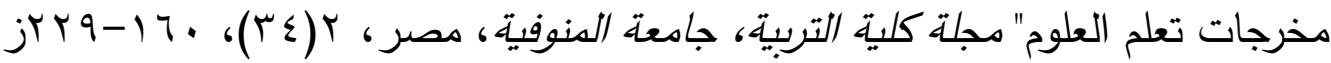

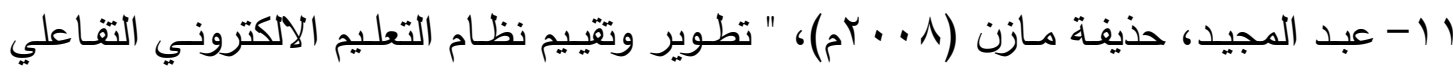
للمواد الدراسية الهندسية والحاسوبية "، رسالة ماجستير ، الاكاديميه العربيـة في الدنمارك، نظم المعلومات الإدارية.

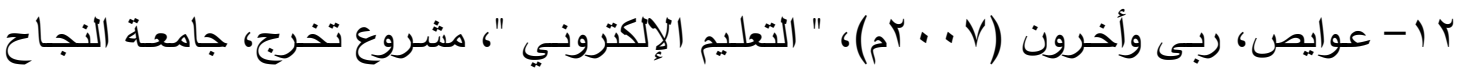
الوطنية، كلية تكنولوجيا المعلومات،تخصص أنظمة المعلومات المحوسبة. با - عوض، حسني وابو بكر، إياد ( • ( • ( م)، " أثر استخدام نمط التعليم المدمج على تحصيل الدارسـين في جامعـة القدس المفتوحسة أثر اسـتخدام نمـط التعليم المـدمج على تحصـيل الدارسين في جامعة القدس المفتوحة / فلسطين "، جامعة القدس المفتوحة. ع ا - محمود، صلاح الدين عرفة.(1 (1 • (1). تعليم وتعلم مهارات التدريس في عصر المعلومات. عالم الكتب: القاهرة.

15- Alebaikan, R. A. (2010). "Perceptions of Blended Learning in Saudi Universities" Ph.D, University of Exeter.

16- Ally, M. (2008): "Foundations of Educational Theory Foronline Learning" in T. Anderson (ED)., The Theory and Practice of Online Learning, Athabasc University, Athabasca, Canada.

17- AyGun, M. (2012). Impact of Blended Learning Environments Based on Algo- Heuristic Theory on Some Variables", Mevlana International Journal of Education (MIJE). 2(2), December. 
أ.أماني العدواني، أ.نورة المجلي دراسة مقارنة فيي مفهو م واتجاهات التعلم الإلكتروني بين طالبات مرحلة الماجستير بكلية التربية

18- Carman, J. (2002). Blended Learning Design: Five Key ingrredients pdf. From: http// www.Knowledsge.com/pdf/Blended Learning Design.

19- Kerres, M. (2003) A Didactical framework for the design of blended Learning arrangements, Journal of Educational Media. 28 (2-3), $101-113$

20- Maguir, P. (2005). Professional development in a blended Learning environment for Middle School Mathematics Teachers, D.A.I, 2244.

21- Saliba, G. \& Cortez, H. (2013). "Fundamentals of Blended Learning" Learning and Teaching Unit (UWS), University of Western Sydney, Australli.

22- Siemens, G.(2005). "Connectivism: A Learning Theory for the Digital Ag”, International Journal of Instructional Technology and Distance Learning 1(2).

23- Yapici, I.U. \&Akbayin, H. (2012). "The Effect of Blended Learning Model on Hifh School Students' Biology Achievement and on Their Attitudes Towards The Internet" The Turkish Online Journal of Educational Technology, 2(22), April 